\title{
System scale analytical modeling of forward and assisted forward osmosis mass exchangers with a case study on fertigation
}

\author{
Leonardo D. Banchik ${ }^{1}$, Adam M. Weiner ${ }^{1}$, Bader Al-Anzi ${ }^{2}$, and John H. \\ Lienhard $\mathrm{V}^{* 1}$ \\ ${ }^{1}$ Rohsenow Kendall Heat Transfer Laboratory, Department of Mechanical \\ Engineering, Massachusetts Institute of Technology, Cambridge MA \\ 02139-4307 USA \\ ${ }^{2}$ College of Life Sciences, Environmental Technologies and Management \\ Department, Kuwait University, Kuwait
}

\begin{abstract}
Forward osmosis (FO) and assisted forward osmosis (AFO) mass exchangers are currently receiving considerable attention for their potential use in a variety of dilution and concentration applications in resource extraction, fertigation, and pharmaceutical process streams. In this work we develop analytical expressions for parallel and counterflow exchangers which can be used to quickly and accurately estimate the membrane area required for dilution and concentration processes in addition to determining the performance of existing exchangers. Unlike previous models, our analytical model accounts for internal and external concentration polarization in system scale exchangers with overall average errors of less than $10 \%$ against a numerical model and less than $35 \%$ validated against data from literature. The performance of FO and AFO exchangers is compared, and an osmotic fertilizer dilution (fertigation) case study is investigated in which the trade-off between energy and membrane area requirements is quantified. We find that AFO exchangers yield a higher recovery relative to FO exchangers for a given energy input especially when the inlet draw-to-feed osmotic pressure ratio is low. We find that diminishing returns in recovery ratio are attained for increasing membrane area and increasing draw-to-feed mass flow rate ratio. We also find that for the same brackish feed water and recovery ratio, reductions in area of up to $40 \%$ relative to $\mathrm{FO}$ can be realized with $2 \mathrm{kWh} / \mathrm{m}^{3}$ of energy input into an AFO system in the fertigation case study.
\end{abstract}

${ }^{*}$ Corresponding author: lienhard@mit.edu

(C) 2016. This manuscript version is made available under the Elsevier user license http://www.elsevier.com/open-access/userlicense/1.0/ 
Keywords: forward osmosis; assisted forward osmosis; effectiveness - number of mass transfer units (MTU); system analysis; fertigation 


\section{Nomenclature}

\section{Roman Symbols}

A mass-based water permeability coefficient, $\mathrm{kg} / \mathrm{m}^{2}-\mathrm{s}-\mathrm{kPa}$

$A_{m} \quad$ total membrane surface area, $\mathrm{m}^{2}$

$A_{s} \quad$ surface area of a membrane section, $\mathrm{m}^{2}$

$B \quad$ salt permeability coefficient, $\mathrm{m} / \mathrm{s}$

CF concentration factor

$D \quad$ diffusion coefficient, $\mathrm{m}^{2} / \mathrm{s}$

DF dilution factor

$E_{\text {spec }} \quad$ specific energy consumption, $\mathrm{kWh} / \mathrm{m}^{3}$

e, $f, g \quad$ variables for Eq. 19

$f_{\text {os }} \quad$ modified van 't Hoff coefficient, $\mathrm{kPa}-\mathrm{kg} / \mathrm{g}$

$k \quad$ average external mass transfer coefficient, $\mathrm{m} / \mathrm{s}$

$K \quad$ average solute resistance to diffusion, $\mathrm{s} / \mathrm{m}$

$\dot{m} \quad$ mass flow rate, $\mathrm{kg} / \mathrm{s}$

MR mass flow ratio

MTU mass transfer units

$\mathrm{N} \quad$ number of discrete elements in numerical model

$P \quad$ hydraulic pressure, $\mathrm{kPa}$

$P^{*} \quad$ pressure ratio

RR recovery ratio

$S \quad$ structural parameter, $\mathrm{m}$

$x \quad$ axial position along membrane, $\mathrm{m}$

$w \quad$ salinity - grams of solute per kilogram of solution, $\mathrm{g} / \mathrm{kg}$

\section{Greek Symbols}

$\beta \quad$ dimensionless area correction factor

$\varepsilon \quad$ effectiveness

$\theta \quad$ osmotic pressure ratio

$\kappa, \lambda \quad$ variables for Eq. 14

$\pi \quad$ bulk osmotic pressure, $\mathrm{kPa}$

$\Pi \quad$ inlet draw-to-feed osmotic pressure ratio

$\rho \quad$ solution density, $\mathrm{kg} / \mathrm{m}^{3}$

\section{Superscripts}

, relating to parallel-flow model

\section{Subscripts}

d draw stream

$f \quad$ feed stream 


$\begin{array}{ll}i & \text { inlet } \\ \max & \text { maximum } \\ o & \text { outlet } \\ p & \text { permeate stream } \\ s & \text { solutes }\end{array}$

\section{Abbreviations}

AFO assisted forward osmosis

FO forward osmosis

NTU number of transfer units

PRO pressure-retarded osmosis

RO reverse osmosis 


\section{Introduction}

Conservation and wastewater reuse are crucial first steps for reducing demand in water stressed regions. Where these efforts are insufficient or unsuccessful, however, desalination can play an essential role in providing fresh water for potable, industrial, or agricultural use. Of the approximately 80 billion liters per day currently produced by desalination, reverse osmosis (RO), a membrane-based system, is responsible for producing more than $60 \%$ [1]. Forward osmosis (FO) desalination systems, another class of membrane-based process, are currently receiving attention in the literature because they operate at low hydraulic pressure differences and are theorized to have a lower fouling potential relative to $\mathrm{RO}[2,3]$.

In FO desalination, FO exchangers are used in the "front-end" of the system. In this process, a feed stream and a draw stream enter a counterflow exchanger in which they are separated by a semi-permeable membrane that allows water to pass through, but not salts. The feed consists of the stream to be concentrated, and the more concentrated (higher osmotic pressure) draw stream is made up of a natural or synthetic solution that is diluted. Pure water permeates through the membrane into the draw stream and the diluted draw stream exiting the FO exchanger enters a "back-end" process, such as a distillation column or an RO system, for recovering the permeate and regenerating the draw solution [4]. Although FO is unlikely to replace RO for seawater desalination [5], researchers are still working to determine its viability for treating produced water $[6,7]$ even though it does not perform well relative to other systems on an energetic basis [8, 9].

Whether FO has a future in desalination is a subject of ongoing research and development, but it can certainly be used effectively for the dilution or concentration of a specific process stream in applications such as fertigation, food production, pharmaceuticals, and mining [3]. This process is especially attractive when the stream to be concentrated or diluted is paired with a "sacrificial" draw or feed stream that does not require a "back-end" regeneration step.

In special cases, a designer may wish to use mechanical work to dilute or concentrate a stream more effectively per unit area of membrane. In these cases, a variation of FO called assisted forward osmosis (AFO) can be used. In the AFO process, the feed stream is pressurized to increase the permeate flux. Figure 1 shows a qualitative plot of the various osmotically driven membrane-based processes obtained by varying the values of hydraulic pressure difference $\Delta P$ for a fixed osmotic pressure difference $\Delta \pi$ so as to change the direction and magnitude of permeate flux. AFO is in quadrant QIII, FO lies at the boundary of QIII and QIV, and RO lies in quadrant QI. PRO, a membrane-based technology for salinity gradient power production, is in quadrant QIV.

The literature on pressure retarded osmosis and FO processes continues to grow, however, fewer investigations of AFO have been conducted. In the literature, the term AFO is also referred to as pressure assisted forward osmosis (PAFO) [11, 12] or pressure assisted osmosis (PAO) [13]. To date, AFO performance has been evaluated by studying the impact of hydraulic pressure on FO membrane properties, which showed a significant increase in water flux while yielding lower reverse solute diffusion than predicted by the solution diffusion model [14]. The effects of hydraulic pressure, membrane properties, and orientation on AFO performance have also been investigated experimentally $[12,15,16]$. 


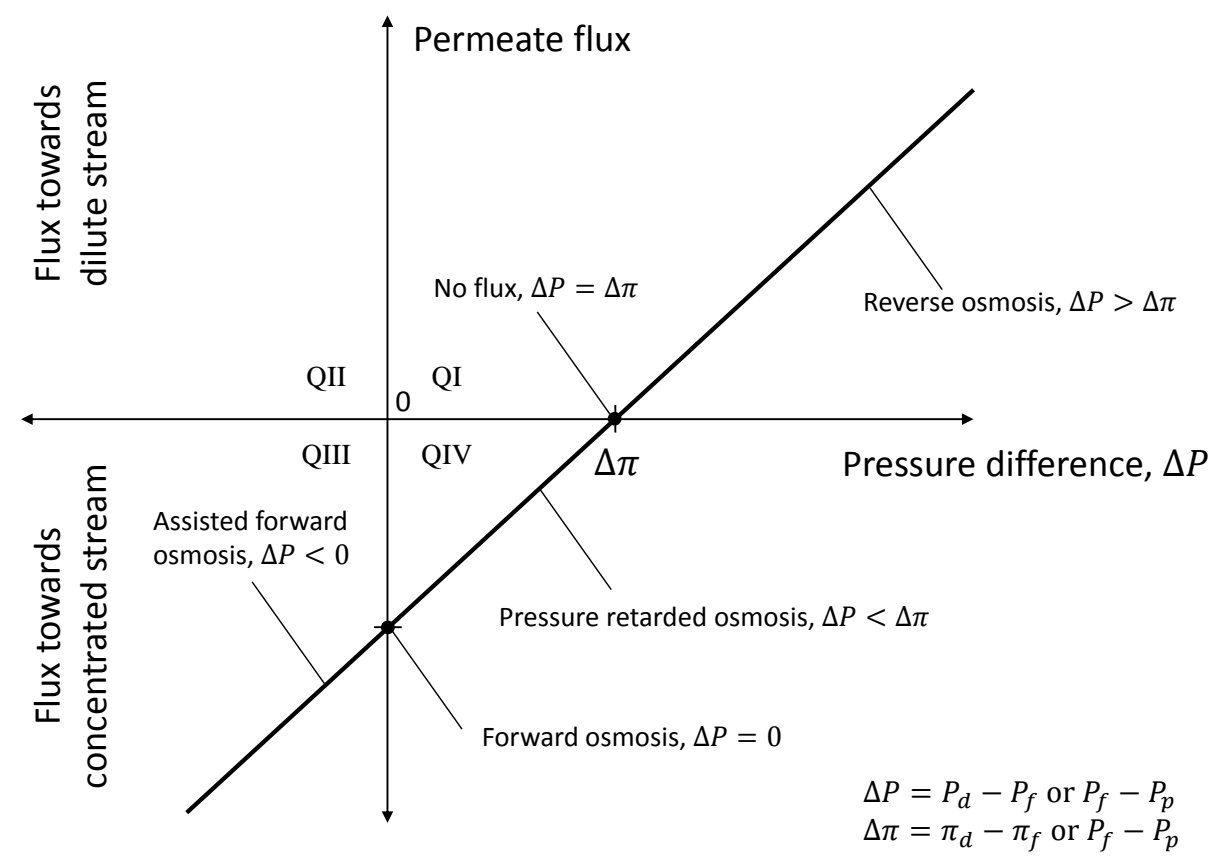

Figure 1: Qualitative plot of the various operating regimes of osmotic membrane-based mass exchangers for a fixed $\Delta \pi$. For AFO, FO, and PR operation $\Delta P=P_{\text {draw }}-P_{\text {feed }}$ and $\Delta \pi=\pi_{\text {draw }}-\pi_{\text {feed }}$. For RO operation $\Delta P=P_{\text {feed }}-P_{\text {permeate }}$ and $\Delta \pi=\pi_{\text {feed }}-\pi_{\text {permeate }}$. Figure adapted from Lee et al. [10].

\subsection{The importance of system scale modeling}

Much of the FO literature, and especially the AFO literature, focuses on lab-scale transport through coupon-sized membranes where the concentrations along the membrane for both streams are constant. This assumption can lead to under-sizing exchangers for use in large systems, because the average osmotic driving force across a long membrane is lower than the maximum osmotic driving force in a zero-dimensional (0-D), or coupon-scale, transport model. A large system must be sized with a model that considers the change in driving force along the length of the membrane.

In this paper, we analytically determine the effect of stream-wise length on the recovery ratio of system scale $\mathrm{FO}$ and $\mathrm{AFO}$ exchangers in both parallel-flow and counterflow. In this model the salinity of each stream, and therefore the osmotic pressure and net driving pressure, is allowed to change over the length of the exchanger. This model is unlike those used in literature which assume that the salinity on both sides of the membrane is not a function of membrane area $[12,17,18]$.

Several studies in literature have addressed multi-dimensional models of FO processes. Sagiv and Semiat, for instance, analyzed the performance of a two-dimensional FO process using computational fluid dynamics [19]. Their model, however, only considered a finite number of operating conditions. Xiao et al. developed expressions to predict the performance and size of FO hollow-fibers using dimensionless parameters [20]. Holloway et al. developed a numerical model for an FO exchanger which accounted for concentration po- 
larization and fouling by reducing the membrane permeability coefficient [21]. Phuntsho et al. used a numerical model to investigate "osmotic equilibrium" in an FO exchanger of a constant size and water and salt permeability which we refer to as an exchanger with an effectiveness of unity [22]. Deshmukh et al. investigated module scale FO system performance and determined performance limits similar to what is presented herein [23]. These studies, however, require numerical integration and do not allow for analytical calculation of performance limit or estimation of membrane area with concentration polarization effects.

Inspired by the effectiveness-number of transfer units $(\varepsilon$-NTU) method used in heat exchanger analysis for decades [24], we derive dimensionless expressions in the following sections which allow researchers to design large FO or AFO counterflow ${ }^{1}$ exchangers to achieve a certain recovery ratio or effectiveness (defined as the recovery ratio divided by the maximum possible recovery ratio). A similar extension of this heat exchanger analogy has been applied to two other osmotically driven membrane processes: RO systems [26] and pressure-retarded osmosis (PRO) systems [25, 27]. Using the presented equations, designers can either 'size' an exchanger given operating conditions (inlet feed and draw mass flow rates, osmotic pressures, and hydraulic pressures) and a desired performance or 'rate' an exchanger given the size and operating conditions of an existing exchanger. Furthermore, we explain how to significantly reduce overall average errors from the analytical model to less than 10\% against a numerical model by mathematically solving for a correction factor $\beta$ which accounts for concentration polarization and nonlinearities in osmotic pressure as a function of salinity. When validated against data from literature, the analytical model yields errors less than $35 \%$. After model development we compare the performance of FO and AFO exchangers and investigate the trade-off between energy and membrane area requirements in an osmotic fertilizer dilution (fertigation) case study.

\section{Zero-dimensional solution diffusion model}

The differential form of the permeate flow rate for an osmotic process in which the permeate diffuses in the direction of increasing concentration is given by Eq. (1) [10]

$$
d \dot{m}_{p}=A[\Delta \pi(x)-\Delta P] \beta d A_{m}
$$

where $d \dot{m}_{p}$ is the differential permeate mass flow rate through the membrane in $\mathrm{kg} / \mathrm{s}, A$ is the mass-based water permeability coefficient of the membrane in $\mathrm{kg} / \mathrm{s}-\mathrm{m}^{2}-\mathrm{kPa}, \Delta \pi(x)$ is the local osmotic pressure difference between the bulk draw and feed streams $\left[\pi_{d}(x)-\pi_{f}(x)\right]$ in $\mathrm{kPa}, \Delta P$ is the local hydraulic pressure difference between the draw and feed $\left(P_{d}-P_{f}\right)$ in $\mathrm{kPa}$, and $d A_{m}$ is the differential membrane surface area in $\mathrm{m}^{2}$. We have included $\beta$, a streamwise average dimensionless correction factor, to account for concentration polarization and non-linearity in the osmotic pressure as a function of salinity. In our previous work [27], we considered a correction factor for the feed and draw stream separately, but here, for simplicity, we consider an average $\beta$ used to de-rate the net driving pressure in an exchanger of finite length. In the ideal case where no internal and external concentration polarization is present and osmotic pressure is linearly proportional to salinity $\beta=1$.

\footnotetext{
${ }^{1}$ We present the parallel-flow configuration equations and results in Appendix B. The counterflow configuration is presented in the main body of this work because it is superior in performance [25].
} 


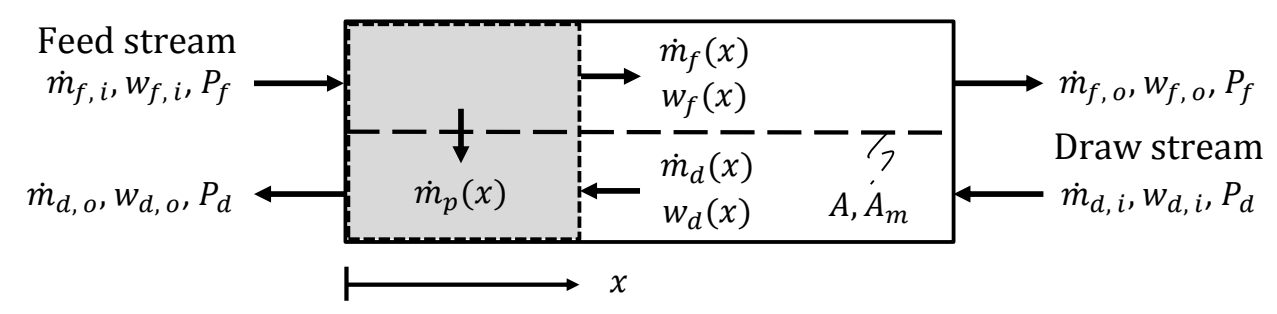

Figure 2: A generic counterflow osmotic mass exchanger with pressurized saline inlets.

We modify Eq. 1 to include van 't Hoff's law in which each stream's osmotic pressure is assumed to be linearly proportional to salinity $w . f_{\mathrm{os}}$ is the salinity-based modified van 't Hoff's coefficient in $\mathrm{kPa}-\mathrm{kg} / \mathrm{g}^{2}$ :

$$
d \dot{m}_{p}=A\left\{f_{\mathrm{os}}\left[w_{d}(x)-w_{f}(x)\right]-\Delta P\right\} \beta d A_{m}
$$

In the following section we will integrate the zero-dimensional solution diffusion model along the length of the exchanger to determine the effects of finite membrane area on performance.

\section{One-dimensional counterflow models}

Under an assumed condition of $100 \%$ salt rejection, only pure water permeates through the membrane; hence the salinity of the permeate is zero and the mass flow rate of salt in the feed stream $\dot{m}_{s, f}$ is conserved. Applying conservation of solute mass to the feed stream between the inlet $\dot{m}_{f, i}$ and an arbitrary location $\dot{m}_{f}(x)$ along the flow channel as shown in Fig. 2 yields

$$
\dot{m}_{s, f}=\dot{m}_{f, i} \times w_{f, i}=\dot{m}_{f}(x) \times w_{f}(x)
$$

For the same arbitrary location, conservation of mass for the entire solution requires that

$$
\dot{m}_{f, i}=\dot{m}_{f}(x)+\dot{m}_{p}(x)
$$

Substituting Eq. (4) into Eq. (3) and solving for $w_{f}(x)$ yields

$$
w_{f}(x)=\frac{\dot{m}_{f, i} \times w_{f, i}}{\dot{m}_{f, i}-\dot{m}_{p}(x)}
$$

Applying similar statements of mass conservation to the draw side, $\dot{m}_{d}$, for the counterflow configuration at the same arbitrary location taken for the feed stream gives the draw salinity as a function of length, $w_{d}(x)$, in Eq. (6):

$$
w_{d}(x)=\frac{\dot{m}_{d, o} \times w_{d, o}}{\dot{m}_{d, o}-\dot{m}_{p}(x)}
$$

Substituting Eqs. (5) and (6) into Eq. (2) yields

\footnotetext{
${ }^{2} f_{\text {os }}$ is determined by locally linearizing the osmotic pressure vs. salinity curve in the salinity range of operational interest.
} 


\begin{tabular}{lc} 
Parameter & Definition \\
\hline Recovery ratio & $\mathrm{RR} \equiv \dot{m}_{p} / \dot{m}_{f, i}$ \\
Mass flow rate ratio & $\mathrm{MR} \equiv \dot{m}_{d, i} / \dot{m}_{f, i}$ \\
Osmotic pressure ratio, feed & $\theta_{f} \equiv \pi_{f, i} / \Delta \pi_{\max }$ \\
Osmotic pressure ratio, draw & $\theta_{d} \equiv \pi_{d, i} / \Delta \pi_{\max }$ \\
Number of mass transfer units & $\mathrm{MTU}_{\pi} \equiv \beta A A_{m} \Delta \pi_{\max } / \dot{m}_{f, i}$ \\
Pressure ratio & $P^{*} \equiv \Delta P / \Delta \pi_{\max }$ \\
Concentration factor, feed & $\mathrm{CF}_{f} \equiv 1 /(1-\mathrm{RR})$ \\
Concentration factor, draw & $\mathrm{CF}_{d} \equiv \mathrm{MR} /(\mathrm{MR}+\mathrm{RR})$ \\
Dilution factor, for case study & $\mathrm{DF} \equiv \mathrm{RR} /(\mathrm{MR}+\mathrm{RR})$
\end{tabular}

Table 1: Dimensionless parameters used in mass exchanger models. The maximum osmotic pressure difference is defined as $\Delta \pi_{\max } \equiv \pi_{d, i}-\pi_{f, i}$ and the hydraulic pressure difference used in the pressure ratio parameter $P^{*}$ is $\Delta P=P_{d}-P_{f}$. The dimensionless correction factor $\beta$ is considered in the number of mass transfer units parameter.

$$
d \dot{m}_{p}=A\left\{f_{\mathrm{os}}\left[\frac{\dot{m}_{d, o} \times w_{d, o}}{\dot{m}_{d, o}-\dot{m}_{p}(x)}-\frac{\dot{m}_{f, i} \times w_{f, i}}{\dot{m}_{f, i}-\dot{m}_{p}(x)}\right]-\Delta P\right\} \beta d A_{m}
$$

The important assumptions underlying this equation are that the water permeability coefficient is constant, the pressure drop through the flow channel is negligible, the membrane rejects $100 \%$ of solutes, and, when $\beta=1$, that concentration polarization effects are negligible and the osmotic pressure is a linear function of salinity.

\subsection{Dimensionless parameters}

Table 1 displays the parameters used to non-dimensionalize the governing equations in this work. Because concentration polarization increases the area required to achieve the same recovery ratio $[26,27]$, the correction factor $\beta$ is included in the number of mass transfer units parameter $\mathrm{MTU}_{\pi}$ to modify the amount of membrane area required when $\beta \neq 1$. For FO operation the pressure ratio parameter $P^{*}=0$ while for AFO operation, $P_{f}>P_{d}$ so that the pressure ratio parameter $P^{*}<0$. The latter represents a case where the feed stream is intentionally pressurized to increase permeate flux.

Two additional parameters are required for the counterflow configuration and can be derived using conservation of mass around the entire exchanger:

Outlet mass flow rate ratio, $\mathrm{MR}_{o}$

$$
\mathrm{MR}_{o} \equiv \frac{\dot{m}_{d, o}}{\dot{m}_{f, i}}=\mathrm{MR}+\mathrm{RR}
$$

Outlet draw osmotic pressure ratio, $\theta_{d, o}$

$$
\theta_{d, o} \equiv \frac{\pi_{d, o}}{\Delta \pi_{\max }}=\theta_{d} \frac{\mathrm{MR}}{\mathrm{MR}+\mathrm{RR}}
$$




\section{Concentration factor, CF}

An additional dimensionless parameter which may be useful to a designer is the concentration factor, a ratio of the outlet salinity of a stream to the inlet salinity. By considering a pure permeate and applying conservation of mass for solution and solutes to the feed and draw streams separately, the expressions for the feed and draw concentration factors can be determined.

For the feed side:

$$
\mathrm{CF}_{f} \equiv \frac{w_{f, o}}{w_{f, i}}=\frac{1}{1-\mathrm{RR}}
$$

For the draw side:

$$
\mathrm{CF}_{d} \equiv \frac{w_{d, o}}{w_{d, i}}=\frac{\mathrm{MR}}{\mathrm{MR}+\mathrm{RR}}
$$

\section{Dilution factor, DF}

The dilution factor, a dimensionless parameter used in our fertigation case study, can also be useful for a designer. We define the dilution factor as a ratio of the draw stream salinity reduction divided by the inlet salinity of the draw stream:

$$
\mathrm{DF}=\frac{w_{d, i}-w_{d, o}}{w_{d, i}}=\frac{\mathrm{RR}}{\mathrm{MR}+\mathrm{RR}}
$$

\subsection{Assisted forward osmosis}

Using the dimensionless groups discussed in Sec. 3.1, Eq. (7) can be rewritten in a dimensionless form as follows:

$$
d \mathrm{RR}=\left(\frac{\mathrm{MR}_{o} \times \theta_{d, o}}{\mathrm{MR}_{o}-\mathrm{RR}}-\frac{\theta_{f}}{1-\mathrm{RR}}-P^{*}\right) d \mathrm{MTU}_{\pi}
$$

Simplification and integration of Eq. 13 with boundary conditions of $\operatorname{RR}(x)=(0, \operatorname{RR})$, $\mathrm{MTU}_{\pi}(x)=\left(0, \mathrm{MTU}_{\pi}\right)$ yields:

$$
\begin{aligned}
\mathrm{MTU}_{\pi} \times P^{*}= & \frac{(\lambda-1)\left(\lambda-\mathrm{MR}_{o}\right)}{(\kappa-\lambda)} \ln \left(\frac{\lambda-\mathrm{RR}}{\lambda}\right) \\
& -\frac{(\kappa-1)\left(\kappa-\mathrm{MR}_{o}\right)}{(\kappa-\lambda)} \ln \left(\frac{\kappa-\mathrm{RR}}{\kappa}\right)-\mathrm{RR}
\end{aligned}
$$

where

$$
\begin{aligned}
\kappa= & \frac{1}{2 P^{*}}\left[P^{*}+\operatorname{MR}_{o}\left(P^{*}-\theta_{d, o}\right)+\theta_{f}\right] \\
& -\frac{1}{2 P^{*}} \sqrt{\left[P^{*}+\mathrm{MR}_{o}\left(P^{*}-\theta_{d, o}\right)+\theta_{f}\right]^{2}+4 P^{*} \mathrm{MR}_{o}\left(-P^{*}+\theta_{d, o}-\theta_{f}\right)} \\
\lambda= & \frac{1}{2 P^{*}}\left[P^{*}+\operatorname{MR}_{o}\left(P^{*}-\theta_{d, o}\right)+\theta_{f}\right] \\
& +\frac{1}{2 P^{*}} \sqrt{\left[P^{*}+\mathrm{MR}_{o}\left(P^{*}-\theta_{d, o}\right)+\theta_{f}\right]^{2}+4 P^{*} \mathrm{MR}_{o}\left(-P^{*}+\theta_{d, o}-\theta_{f}\right)}
\end{aligned}
$$


Equations $(14-16)$ are the same dimensionless expressions for the counterflow PRO model given in [27]. In this work, however, we take $\Delta P<0$ and, consequently, $P^{*}<0$. These equations can be used to either size an exchanger using the functional relationship:

$$
\mathrm{MTU}_{\pi}=\mathrm{fn}\left(\mathrm{RR}, \mathrm{MR}, \theta_{d}, \theta_{f}, P^{*}\right)
$$

or to rate an exchanger using:

$$
\mathrm{RR}=\mathrm{fn}\left(\mathrm{MR}, \theta_{d}, \theta_{f}, \mathrm{MTU}_{\pi}, P^{*}\right)
$$

Figure 3 shows the recovery ratio attainable as a function of $\mathrm{MTU}_{\pi}$ for contours of MR, $\theta_{d}=2$ and $\theta_{f}=1$, and a pressure difference of feed to draw equal to the maximum osmotic pressure difference $P^{*}=-1$. The choice of parameters represents a case where the draw osmotic pressure is two times greater than the feed, such as for a seawater feed stream and brine from a seawater desalination system with $R R=0.5$.

There are diminishing returns on the recovery ratio for increasing values of $\mathrm{MR}$ and recovery ratios for $\mathrm{MR}=4$ are essentially equal to those attained at $\mathrm{MR}=3$. Designers should ensure that systems operate at the 'knee' of these curves to maximize performance while minimizing costs. Figure 3 also clearly shows that as $\mathrm{MTU}_{\pi}$ increases, each $\mathrm{MR}$ contour approaches a maximum recovery ratio. We will see in the next section that the effectiveness of the exchanger is unity where the maximum recovery ratio is attained. As shown in Appendix B, counterflow outperforms the parallel-flow configuration for all MR contours (cf. Fig. 3 and Fig. 15).

\subsection{Forward osmosis}

To determine the expression for performance of a counterflow FO exchanger, we rewrite Eq. (13) with $P^{*}=0$ :

$$
d \mathrm{RR}=\left(\frac{\mathrm{MR}_{o} \times \theta_{d, o}}{\mathrm{MR}_{o}-\mathrm{RR}}-\frac{\theta_{f}}{1-\mathrm{RR}}\right) d \mathrm{MTU}_{\pi}
$$

Equation (17) can be simplified and integrated:

$$
\int_{0}^{\mathrm{RR}} \frac{\left(\mathrm{MR}_{o}-\mathrm{RR}\right)(1-\mathrm{RR})}{\mathrm{MR}_{o} \theta_{d, o}(1-\mathrm{RR})-\theta_{f}\left(\mathrm{MR}_{o}-\mathrm{RR}\right)} d \mathrm{RR}=\mathrm{MTU}_{\pi}
$$

Evaluating this integral yields the following result:

$$
\begin{aligned}
\mathrm{MTU}_{\pi}= & \frac{\mathrm{MR}_{o}}{f} \ln \left|\frac{g}{e}\right|+\left(1+\mathrm{MR}_{o}\right)\left(\frac{\mathrm{RR}}{f}+\frac{e}{f^{2}} \ln \left|\frac{g}{e}\right|\right) \\
& +\frac{1}{f^{3}}\left[e^{2}\left(\ln \left|\frac{g}{e}\right|+\frac{3}{2}\right)+\frac{g^{2}}{2}-2 e g\right]
\end{aligned}
$$

where 


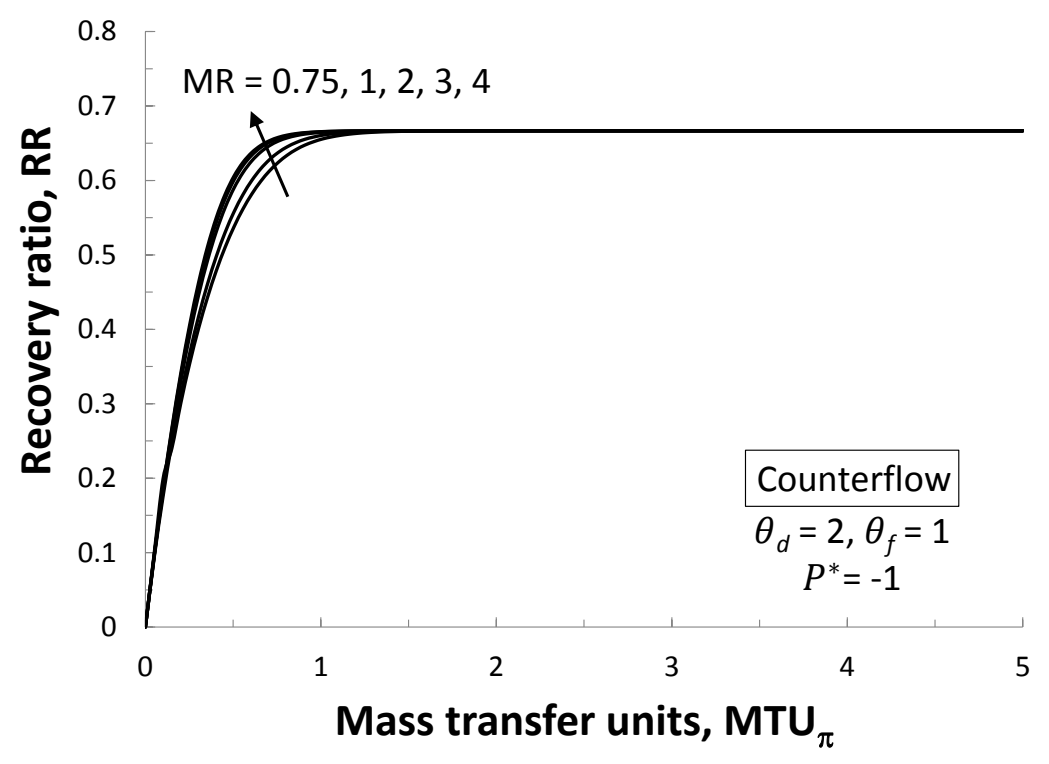

Figure 3: Recovery ratio vs. mass transfer units with contours of mass flow rate ratio for a counterflow AFO exchanger where $-\Delta P=\Delta \pi_{\max }$, i.e. $P^{*}=-1$. This represents a case where brine from a seawater desalination process operating at $\mathrm{RR}=0.5$ is diluted by a seawater feed which is pressurized to the osmotic pressure difference between the inlet brine and feed.

$$
\begin{aligned}
& e=\mathrm{MR}_{o}\left(\theta_{d, o}-\theta_{f}\right) \\
& f=\theta_{f}-\mathrm{MR}_{o} \theta_{d, o} \\
& g=e+f \times \mathrm{RR}
\end{aligned}
$$

Equations (19 - 22) can be used to either size an exchanger using the functional relationship:

$$
\mathrm{MTU}_{\pi}=\mathrm{fn}\left(\mathrm{RR}, \mathrm{MR}, \theta_{d}, \theta_{f}\right)
$$

or to rate an exchanger using:

$$
\mathrm{RR}=\mathrm{fn}\left(\mathrm{MR}, \theta_{d}, \theta_{f}, \mathrm{MTU}_{\pi}\right)
$$

Figure 4 shows the variation of the recovery ratio $\mathrm{RR}$ with the mass transfer units $\mathrm{MTU}_{\pi}$ at different mass flow rate ratios for the counterflow configuration. A draw stream salinity of twice the feed stream salinity is considered. As shown in Appendix B (cf. Fig. 4 and Fig. 17), the counterflow configuration outperforms the parallel-flow configuration for all MR contours. This result is expected and is analogous to the result obtained for heat exchangers. Figure 4 also shows diminishing returns in performance as MR increases beyond two for the values of $\theta_{d}$ and $\theta_{f}$ chosen. 


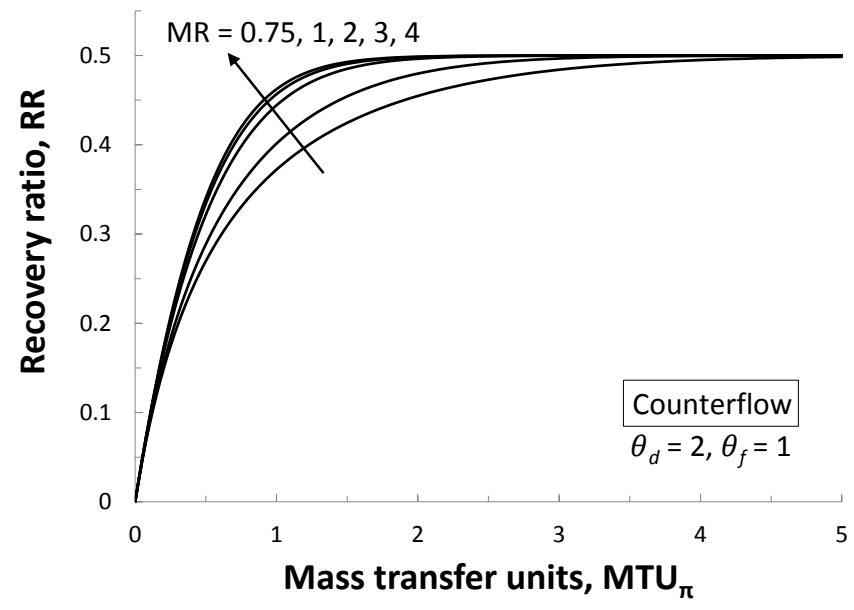

Figure 4: Recovery ratio vs. mass transfer units with contours of mass flow rate ratio for a counterflow FO exchanger. This represents a case where brine from a seawater desalination process operating at $\mathrm{RR}=0.5$ is diluted by a seawater feed.

As shown in Figs. 3 and 4, the recovery ratios attainable with AFO are higher than FO for fixed $P^{*}, \mathrm{MR}$, and $\mathrm{MTU}_{\pi}$. Additionally, for any value of $P^{*}<0$, an AFO exchanger can attain the same recovery ratio with a smaller dimensionless area $\left(\mathrm{MTU}_{\pi}\right)$ than an $\mathrm{FO}$ exchanger. For instance, with $\mathrm{MR}=1$ a recovery ratio of $40 \%$ is attainable with $\mathrm{FO}$ at $\mathrm{MTU}_{\pi}=1$ whereas an AFO exchanger operating at $P^{*}=-1$ can achieve the same recovery ratio with $71 \%$ less area $\left(\mathrm{MTU}_{\pi}=0.29\right)$. Thus, a trade-off exists whereby a higher recovery ratio can be attained with smaller membrane areas at the cost of greater energy consumption to pressurize the feed. This trade-off will be further explored in the fertigation case study in Sec. 6 .

\section{Maximum Recovery Ratio and Effectiveness}

In this section, we derive analytical expressions for the maximum amount of permeate attainable from a system scale AFO and FO mass exchanger. The effectiveness of an osmotic mass exchanger is equivalent to the actual amount of permeate divided by the maximum possible amount of permeate. The effectiveness can also be defined as the recovery ratio divided by the maximum recovery ratio, as shown in Eq. (23):

$$
\varepsilon \equiv \frac{\mathrm{RR}}{\mathrm{RR}_{\max }}
$$

The maximum possible amount of permeate is achieved when the membrane area is large enough to allow the hydraulic and osmotic driving potentials to become equal, or when $\mathrm{MTU}_{\pi}$ increases towards infinity. 


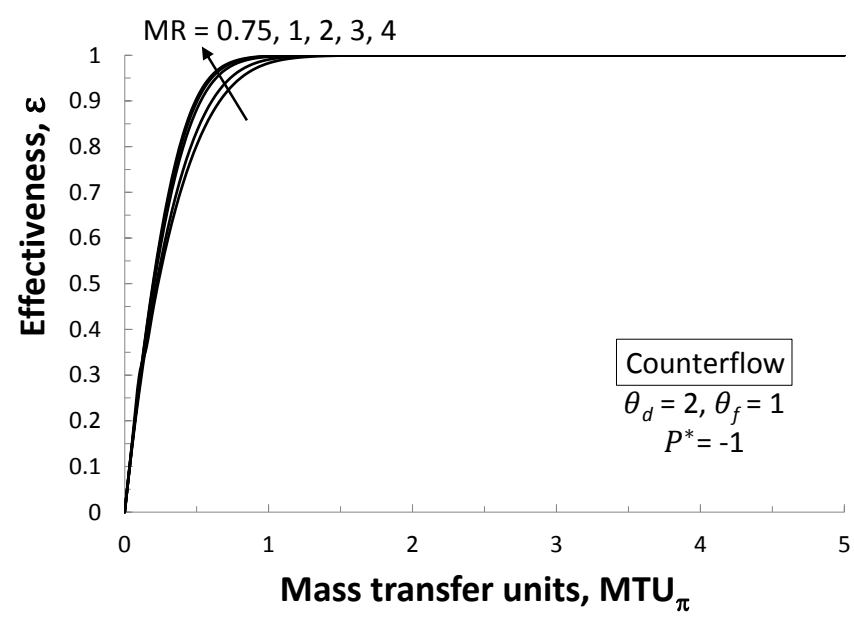

Figure 5: Effectiveness vs. mass transfer units with contours of mass flow rate ratio for a counterflow AFO exchanger where $-\Delta P=\Delta \pi_{\max }$, i.e. $P^{*}=-1$. This represents a case where brine from a seawater desalination process operating at $R R=0.5$ is diluted by a seawater feed which is pressurized to the osmotic pressure difference between the inlet brine and feed.

\subsection{Assisted forward osmosis}

As shown in Sharqawy et al. [25], the maximum recovery will occur when the hydraulic pressure difference is equal to the osmotic pressure difference at the outlet. For a counterflow AFO mass exchanger, there are two local maximum recovery ratios which are found depending on which side of the exchanger first reaches equilibrium. Equations (24) and (25) show these two local maxima [27]:

$$
\begin{aligned}
& \mathrm{RR}_{\text {max }, 1}=\operatorname{MR}\left(\frac{\theta_{d}}{P^{*}+\theta_{f}}-1\right) \\
& \mathrm{RR}_{\max , 2}=1-\frac{\theta_{f}}{\theta_{d}-P^{*}}
\end{aligned}
$$

The lesser of these local maximum recovery $\operatorname{ratios}^{3}$ is the global maximum $\mathrm{RR}_{\max }$ :

$$
\mathrm{RR}_{\max }=\min \left\langle\left|\mathrm{RR}_{\max , 1}\right|,\left|\mathrm{RR}_{\max , 2}\right|\right\rangle
$$

The effectiveness is defined in Eq. (23) and is plotted versus $\mathrm{MTU}_{\pi}$ for the counterflow configuration in Fig. 5.

Closed form solutions for the maximum concentration factor (CF) and dilution factor (DF) for a counterflow AFO system can be attained by substituting the global maximum $\mathrm{RR}_{\max }$ from Eq. (26) into Eqs. (10 - 12).

\footnotetext{
${ }^{3}$ The absolute value of the local maximum recovery ratio is considered because for $P^{*}<0$ values of $\mathrm{RR}_{\max , 1}$ less than zero can result.
} 


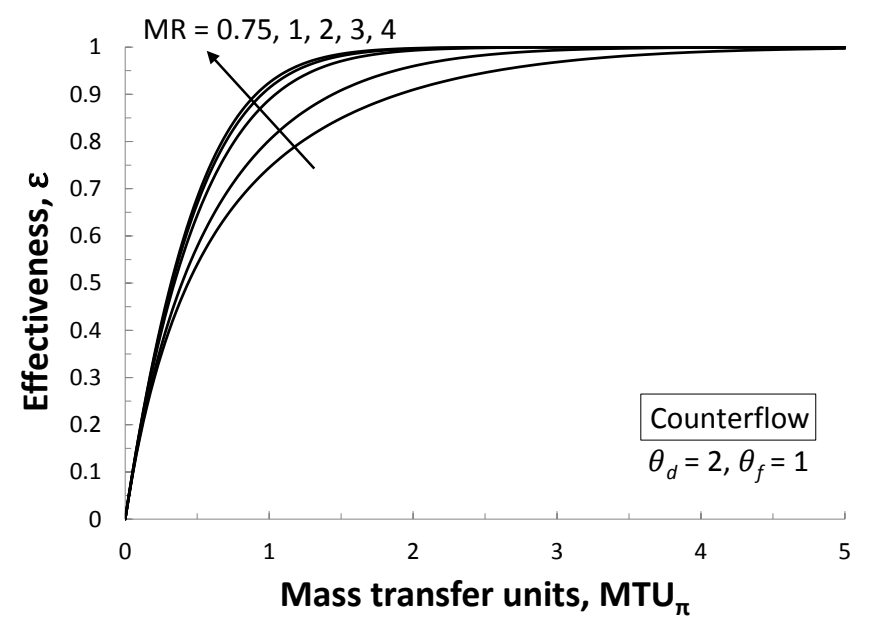

Figure 6: Effectiveness vs. mass transfer units with contours of mass flow rate ratio for a counterflow FO exchanger. This represents a case where brine from a seawater desalination process operating at $\mathrm{RR}=0.5$ is diluted by a seawater feed.

\subsection{Forward osmosis}

To find the maximum recovery of a counterflow FO exchanger, the osmotic driving potential is set to zero on the side of the exchanger which yields a lower RR. On the feed inlet side:

$$
\pi_{d, o}-\pi_{f, i}=0
$$

Using the van 't Hoff model and applying conservation of solution and solutes, this condition will lead to

$$
\mathrm{RR}_{\max , 1}=\operatorname{MR}\left(\frac{\theta_{d}}{\theta_{f}}-1\right)
$$

On the draw inlet side:

$$
\pi_{d, i}-\pi_{f, o}=0
$$

and

$$
\mathrm{RR}_{\max , 2}=1-\frac{\theta_{f}}{\theta_{d}}
$$

We again take the minimum recovery ratio to equal the global maximum $\mathrm{RR}_{\max }$ :

$$
\mathrm{RR}_{\max }=\min \left\langle\mathrm{RR}_{\max , 1}, \mathrm{RR}_{\max , 2}\right\rangle
$$

The effectiveness is defined in Eq. (23) and is plotted versus $\mathrm{MTU}_{\pi}$ for the counterflow configuration in Fig. 6.

Closed form solutions for the maximum concentration factor $(\mathrm{CF})$ and dilution factor (DF) for a counterflow FO system can be attained by substituting the global maximum $\mathrm{RR}_{\max }$ from Eq. (31) into Eqs. (10 - 12). 


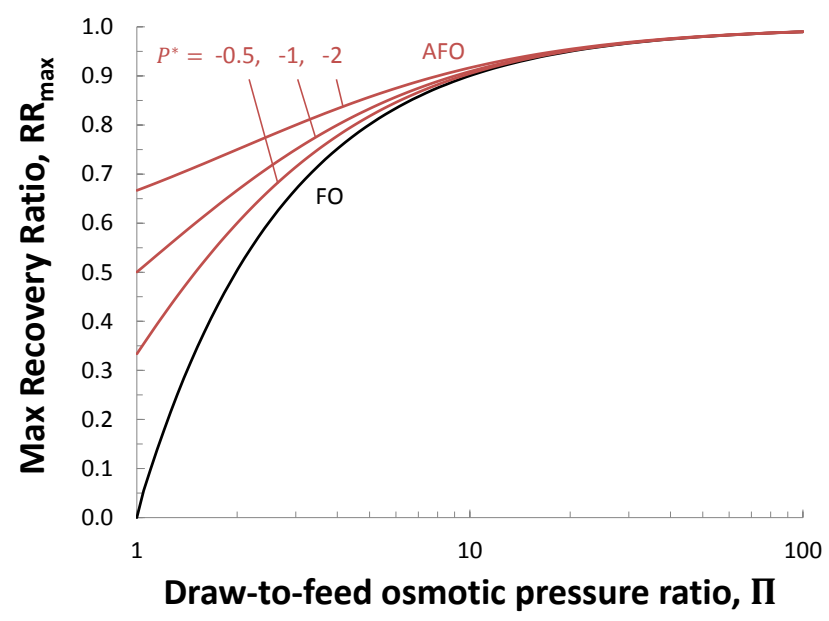

Figure 7: Maximum recovery ratio $R_{\max }$ vs. inlet draw-to-feed osmotic pressure ratio $\Pi$ attainable by counterflow FO and AFO exchangers with varying $P^{*}$ for values of $\mathrm{MR}>1$. For AFO cases $\theta_{f}$ is unity.

\subsection{Effect of osmotic pressure ratios on maximum recovery ratio and system size}

We now illustrate how these analytical expressions can be used to understand system performance limits and size requirements with a variety of draw and feed osmotic pressures. Defining an inlet draw-to-feed osmotic pressure ratio,

$$
\Pi \equiv \frac{\pi_{d, i}}{\pi_{f, i}}=\frac{\theta_{d}}{\theta_{f}}
$$

Fig. 7 shows the maximum recovery ratio attainable from an FO and AFO exchanger with varying inlet draw-to-feed osmotic pressure ratios $\Pi$ and pressure ratios $P^{*}$ for values of $\mathrm{MR}>1$. Red is used to distinguish AFO systems and $\theta_{f}$ is unity for these systems. We can see that for $\mathrm{FO}$, low values of maximum recovery ratio result from low draw-to-feed osmotic pressure ratios. For an FO exchanger to attain recovery ratios greater than $25 \%$, the inlet draw osmotic pressure must be at least 33\% greater than the inlet feed osmotic pressure. Additionally, there are diminishing returns to maximum recovery ratio for increasing $\Pi$. Most importantly, we find that pressurizing the feed stream has a larger effect on increasing the maximum recovery ratio at lower $\Pi$. This is because for low values of $\Pi$, the hydraulic driving force plays a larger role in permeate production than the smaller osmotic driving force. Although not shown in Fig. 7, decreasing $\theta_{f}$ for the AFO cases increases the maximum recovery ratio attainable at low values of $\Pi$.

Figure 8 shows the dimensionless area requirement $\mathrm{MTU}_{\pi}$ versus $\Pi$ for $\mathrm{FO}$ and $\mathrm{AFO}$ exchangers with a fixed exchanger effectiveness of $90 \%$, values of $\mathrm{MR}>1$, and correction factor $\beta=1$. For the AFO cases, $\theta_{f}$ is unity. We can see that higher $\Pi$ values result in an increasing osmotic driving force which lowers system size requirements and that higher values of $\mathrm{MR}$ reduce the $\mathrm{MTU}_{\pi}$ requirement as well. Similar results for the FO case have 


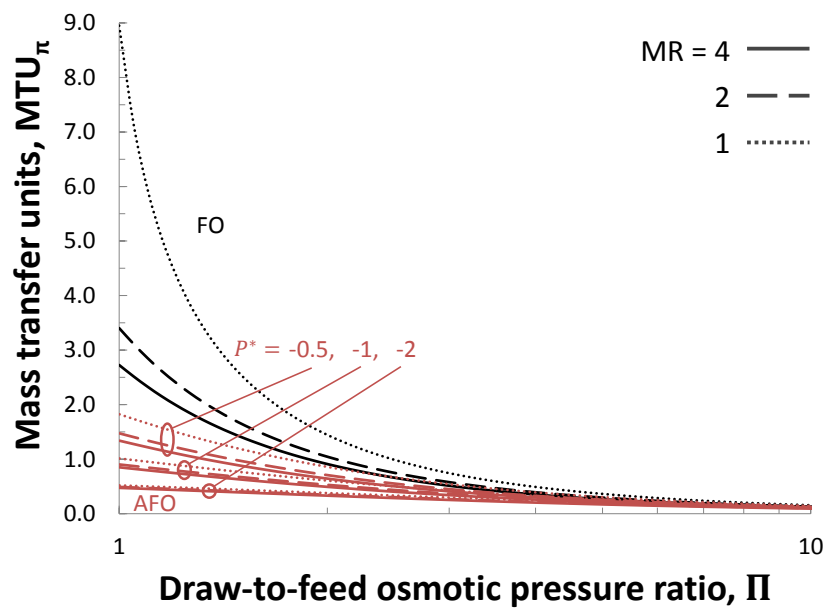

Figure 8: Dimensionless area requirement $\mathrm{MTU}_{\pi}$ vs. inlet draw-to-feed osmotic pressure ratio $\Pi$ for $\mathrm{FO}$ and AFO systems with a fixed exchanger effectiveness of $90 \%$. Contours of varying $\mathrm{MR}$ and $P^{*}$ are shown and $\theta_{f}$ is unity for $\mathrm{AFO}$ cases.

been found by other groups via numerical analysis [23]. For the AFO cases, pressurizing the feed can further reduce system size requirements more significantly for lower $\Pi$. Because these expressions do not consider concentration polarization, systems with a high $\Pi$ require very low values of $\mathrm{MTU}_{\pi}$ to attain high recoveries. In reality, however, systems at high $\Pi$ will require greater membrane areas. We will see in the next section how these models can account for concentration polarization.

\section{Solving for $\beta$}

Internal and external concentration polarization result in significant reductions in flux for osmotic mass exchangers and it is crucial to consider them when designing exchangers [10]. Invoking the van 't Hoff relation can result in additional errors. A straightforward method is provided here for calculating a single value of $\beta$ which reduces the error of the analytical model relative to a numerical model which takes into account concentration polarization and a nonlinear function of osmotic pressure with salinity. In order to obtain a one-to-one mapping of the analytical to numerical model, $\beta$ must be numerically obtained as a function of membrane area as was done in [26]. We find, however, that using a single value of $\beta$ determined for a very small exchanger reduces errors when designing for larger areas. This greatly enhances the usefulness of the analytical model and allows designers to account for concentration polarization without building a numerical model.

To solve for $\beta$, we first we solve for the recovery ratio of a small membrane considering internal and external concentration polarization. Considering these losses requires us to know whether the support layer of the membrane faces the feed or draw stream. The resultant recovery ratio is then used in the analytical model for a finite FO or AFO exchanger and, using the same operating conditions as in the $0-\mathrm{D}$ case, $\beta$ is the remaining unknown variable 
in the models and can be obtained explicitly.

\subsection{Step 1. Solve for RR of a small membrane with concentration polarization}

Most commercial membranes are asymmetric and are comprised of a dense active layer and a porous support layer. Designers can choose whether the support layer of the FO/AFO membrane faces the feed solution (referred to as PRO mode) or draw solution (FO mode) [28]. This choice affects where and to what extent internal and external concentration polarization play a role in reducing the net driving pressure, and consequently flux, through the membrane. It has been generally understood that FO mode provides less flux and less fouling and PRO mode provides more flux and more fouling for given inlet osmotic pressures. Although recent work has shown that FO mode can provide a greater flux and lower fouling with certain draw solutions at low inlet draw-to-feed osmotic pressure ratios $\Pi$ [29], we focus on PRO mode in this section and in the fertigation case study. The same approach for calculating $\beta$ can be used for FO mode, however.

The zero-dimensional model of permeate flux through a membrane element in the PRO mode orientation with a given sectional area $A_{s}$ is:

$$
\dot{m}_{p}=A\left[\pi_{d, i} \exp \left(-\frac{\dot{m}_{p}}{k_{d} \rho_{p} A_{s}}\right)-\pi_{f, i} \exp \left(\frac{\dot{m}_{p} K}{\rho_{p} A_{s}}\right)-\Delta P\right] A_{s}
$$

where $k_{d}$ is the external mass transfer coefficient for the draw side $(\mathrm{m} / \mathrm{s}), K$ is the solute resistance to mass transfer in the porous layer $(\mathrm{s} / \mathrm{m})$, and $\rho_{p}$ is the density of the permeate (assumed to be pure water). $K$ is determined by the ratio of the membrane structural parameter $S$ and the solute self diffusion coefficient of the solution in the support layer $D$.

Equation 33 is solved implicitly for $\dot{m}_{p}$ given the membrane permeability coefficient, the operating conditions of the exchanger $(\Delta P<0$ for $\mathrm{AFO}$ and $\Delta P=0$ for $\mathrm{FO})$, and considering that $A_{s}$ is very small $\left(A_{s}=1 \times 10^{-3} \mathrm{~m}^{2}\right)$.

To summarize, the functional relationship for solving Step 1 is:

$$
\mathrm{RR}=\mathrm{fn}\left(\dot{m}_{f, i}, A, k_{d}, K, \rho_{p}, \pi_{d, i}, \pi_{f, i}, \Delta P, A_{s}=1 \times 10^{-3} \mathrm{~m}^{2}\right)
$$

\subsection{Step 2. Solve for $\beta$ using analytical models}

By using the RR obtained with the procedure of Sec. 5.1 with the same inlet conditions and cross-sectional area in the FO or AFO analytical models given in Eqs. (19 - 22) and Eqs. (14 16), respectively, we can explicitly solve for $\beta$ which lies within the $\mathrm{MTU}_{\pi}$ parameter.

The functional relationship for Step 2 is:

$$
\beta=\mathrm{fn}\left(\dot{m}_{f, i}, A, \mathrm{RR}, \theta_{d}, \theta_{f}, P^{*}, \Delta \pi_{\max }, A_{m}=1 \times 10^{-3} \mathrm{~m}^{2}\right)
$$

For very small exchangers, $\mathrm{RR}$ and $\beta$ are independent of $\mathrm{MR}$ and therefore $\mathrm{MR}$ is not included in the above functional relationship. This single value of $\beta$ can now be used to better approximate the performance of larger exchangers with the analytical model. The reduction in errors possible using this approach will be demonstrated in the fertigation case study in the following section. 
By solving for $\beta$, both AFO and FO analytical models are found to yield average errors of $34.91 \%$ when validated against empirical data found in literature as shown in Appendix A.

\section{Case study: Fertigation}

By examining a specific test scenario, we show the utility of the effectiveness-MTU method for designing FO and AFO systems; and we also gain insight into a specific application. Here, we explore the use of FO and AFO systems to dilute concentrated fertilizer, a process known as fertigation. In this process, water is transported from a locally available brackish (groundwater) or seawater feed across a salt-rejecting membrane to a concentrated fertilizer solution by osmosis or by assisted forward osmosis with the application of additional hydraulic pressure to the feed side. The diluted fertilizer solution is then used for irrigation. Our analysis estimates the required membrane area to achieve a desired dilution factor (DF), which is defined as the percent reduction in fertilizer salinity for a representative groundwater and seawater feed. It also quantifies the energy requirements and area reduction benefits of AFO systems, the accuracy of the simplified analytical model, and compares the groundwater and seawater feed cases.

For the model, we set fixed inputs for the water permeability coefficient $\left(A=2.78 \times 10^{-6}\right.$ $\mathrm{kg} / \mathrm{m}^{2}$-s-kPa or $1 \mathrm{~L} / \mathrm{m}^{2}$-hr-bar [22]), structural parameter $\left(S=340 \times 10^{-6} \mathrm{~m}\right)^{4}$, inlet osmotic pressure of the draw solution (for $2 \mathrm{M}$ or $138 \mathrm{ppt} \mathrm{KCl}$ solution [22]), inlet osmotic pressure of the feed solution (for $35 \mathrm{ppt}$ and $1.5 \mathrm{ppt} \mathrm{NaCl}$ solution for seawater and groundwater, respectively [30]), temperature of the streams $\left(25^{\circ} \mathrm{C}\right)$, and inlet mass flow rate of the feed $\left(\dot{m}_{f, i}=1 \mathrm{~kg} / \mathrm{s}\right)$. As was assumed for the analytical models, hydraulic pressure was maintained as constant throughout the exchanger and salt permeation through the membrane is negligible resulting in a salt permeability coefficient of zero $(B=0 \mathrm{~m} / \mathrm{s})$.

\subsection{Numerical model}

A finite difference numerical model which considers osmotic pressure as a nonlinear function of salinity as well as external and internal concentration polarization is used to determine the accuracy of the simplified analytical model. For the numerical model, we will also use representative values for the average external mass transfer coefficient for the draw side $\left(k_{d}=1.74 \times 10^{-5} \mathrm{~m} / \mathrm{s}[28]\right)$, and average solute resistance to mass transfer for a membrane operated in PRO mode $\left(K=2.24 \times 10^{5} \mathrm{~s} / \mathrm{m}[28]\right)$. The local permeate mass flow rate through a section of membrane with area $A_{s}$ is given by the well known solution diffusion equation with concentration polarization moduli for a membrane operated in PRO mode:

$$
\dot{m}_{p}(x)=A\left[\pi_{d}(x) \exp \left(-\frac{\dot{m}_{p}(x)}{k_{d} \rho_{p} A_{s}}\right)-\pi_{f}(x) \exp \left(\frac{\dot{m}_{p}(x) K}{\rho_{p} A_{s}}\right)-\Delta P\right] A_{s}
$$

Equation 34 is numerically solved over $N=50$ discrete elements each having a sectional area $A_{s}=A_{m} / N$ using Engineering Equation Solver [31]. Conservation of mass is used to

\footnotetext{
${ }^{4}$ Structural parameter was calculated by $S=K D$ assuming that an average diffusion coefficient of $D=1.52 \times 10^{-9} \mathrm{~m}^{2} / \mathrm{s}$ is taken for $\mathrm{NaCl}$ feed solutions in the range of interest.
} 


\begin{tabular}{|c|c|c|c|}
\hline $\begin{array}{l}\text { Brackish feed case } \\
\text { Energy input }\left(\mathrm{kWh} / \mathrm{m}^{3}\right)\end{array}$ & $\beta$ & $\begin{array}{l}\text { Seawater feed case } \\
\text { Energy input }\left(\mathrm{kWh} / \mathrm{m}^{3}\right)\end{array}$ & $\beta$ \\
\hline 0.0 & 0.421 & 0.0 & 0.218 \\
\hline 0.5 & 0.414 & 0.5 & 0.206 \\
\hline 1.0 & 0.403 & 1.0 & 0.195 \\
\hline 2.0 & 0.373 & 2.0 & 0.177 \\
\hline
\end{tabular}

Table 2: Values for $\beta$ for the FO and AFO fertigation cases.

connect each element. The total permeate mass flow rate is then divided by the inlet feed mass flow rate to calculate the system recovery ratio.

With the above parameters specified, the membrane area may be broken out from the expression for $\mathrm{MTU}_{\pi}$. The dilution factor DF is given by Eq. 12 .

To maximize the recovery ratio, we fix the mass flow rate ratio to $\mathrm{MR}=4$. To maximize the exergetic efficiency of the exchanger, one may wish to instead fix the mass flow rate ratio closer to unity [9]. For the AFO case, we express the specific energy consumption (in $\mathrm{kWh} / \mathrm{m}^{3}$ ) for pressurizing the feed with an isentropic pump as

$$
E_{\text {spec }}=-\frac{\Delta P}{3600}
$$

where $\Delta P$ is the applied pressure difference between the draw and feed solutions (in $\mathrm{kPa}$ ). Values of $\beta$ for the FO and AFO cases are found using the method detailed in Section 5 and displayed in Table 2.

\subsection{Case study results}

Figure 9 shows how the dilution factor varies with membrane area for FO and AFO systems employing a groundwater feed. The solid lines represent results generated by the analytical model with $\beta=1$, dashed lines represent results generated by the analytical model where $\beta$ varies, and dotted lines represent results from the numerical model. Red is used to distinguish AFO systems and three different work inputs are considered. The maximum dilution factor in all cases is similar: approximately $20 \%$. To achieve this dilution factor, an FO system requires approximately $118 \mathrm{~m}^{2}$ of membrane area (according to the numerical results). By supplying $0.5 \mathrm{kWh} / \mathrm{m}^{3}$ of work in a comparable AFO system, the area requirement can be reduced to $96 \mathrm{~m}^{2}$, a roughly $19 \%$ reduction in area. Supplying $2 \mathrm{kWh} / \mathrm{m}^{3}$ of work requires only $72 \mathrm{~m}^{2}$, a nearly $40 \%$ reduction in area. At such high input energies, however, it may be more advantageous to simply desalinate the brackish feed by using an RO system and use the fresh permeate to dilute the fertilizer via mixing. Additionally, decreasing the membrane area via an increase in feed pressure using AFO will increase local permeate flux throughout the exchanger which will likely increase fouling. These considerations are beyond the scope of the present work.

For a given dilution factor, the membrane area requirement decreases as more work is provided. Interestingly, however, we observe virtually no increase in the maximum achievable dilution factor with additional work. When a seawater feed is modeled, as in Fig. 10, we see 


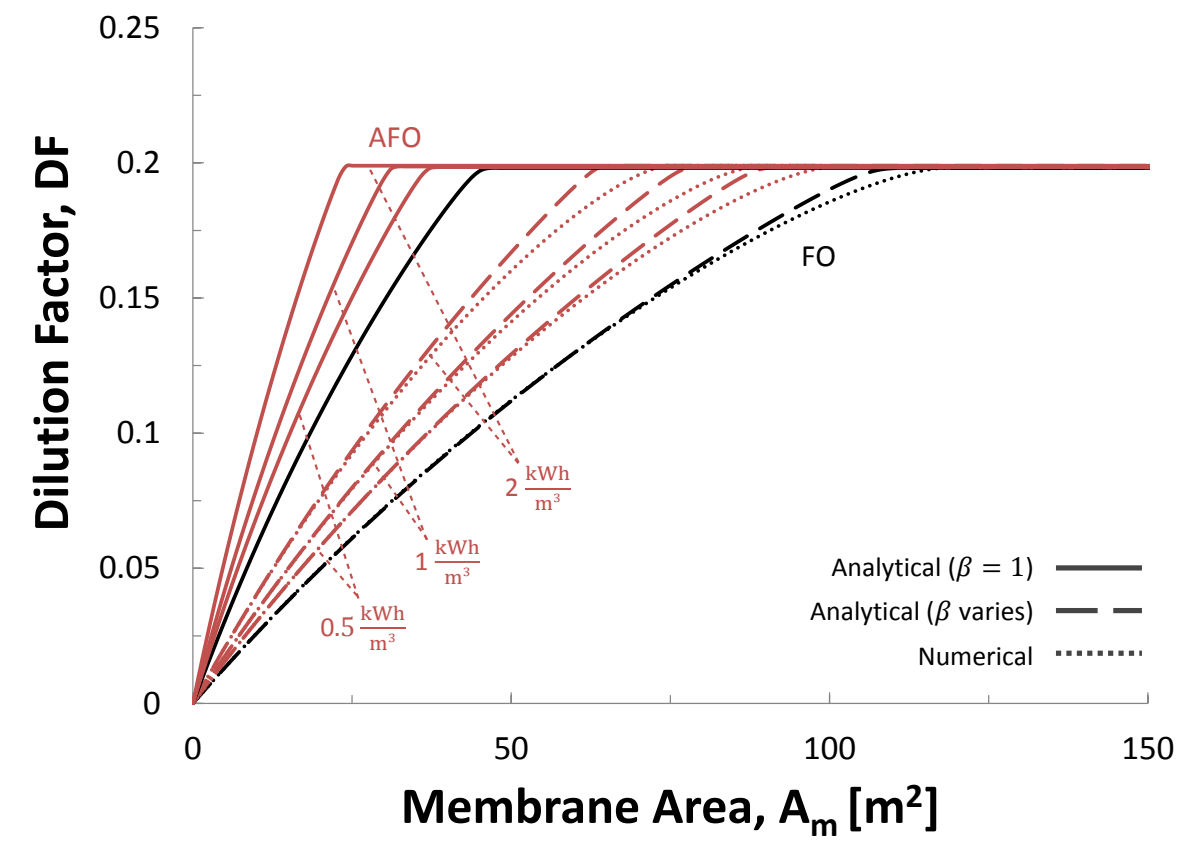

Figure 9: The membrane area requirement of forward osmosis (black line) and assisted forward osmosis systems (red lines) for a fertigation process with a groundwater (1.5 ppt) feed, unity feed flow rate, and $\mathrm{MR}=4$. The analytical results with $\beta=1$ are presented with solid lines, analytical results with varying $\beta$ are presented with dashed lines, and numerical results are presented with dotted lines. 
that providing work both reduces the required membrane area and increases the maximum achievable dilution factor. The two cases together are shown graphically in Fig. 11, which is a plot of the maximum recovery ratio (Eqs. 26 and 31) versus applied pressure (as opposed to work provided). In the groundwater case, the FO process already recovers nearly all of the water from the feed stream, diluting the draw to the fullest extent. No further improvements in recovery may be realized by any means, even by applying pressure. For a given configuration, however, the groundwater feed results in a significantly higher dilution factor due to a larger maximum osmotic pressure difference. This result is in line with the limits of recovery ratio explored in Fig. 7: for a fixed draw stream osmotic pressure the seawater feed has a lower inlet draw-to-feed osmotic pressure ratio $\Pi$ than the groundwater feed so that pressurizing the feed stream has a greater effect in increasing the maximum recovery ratio.

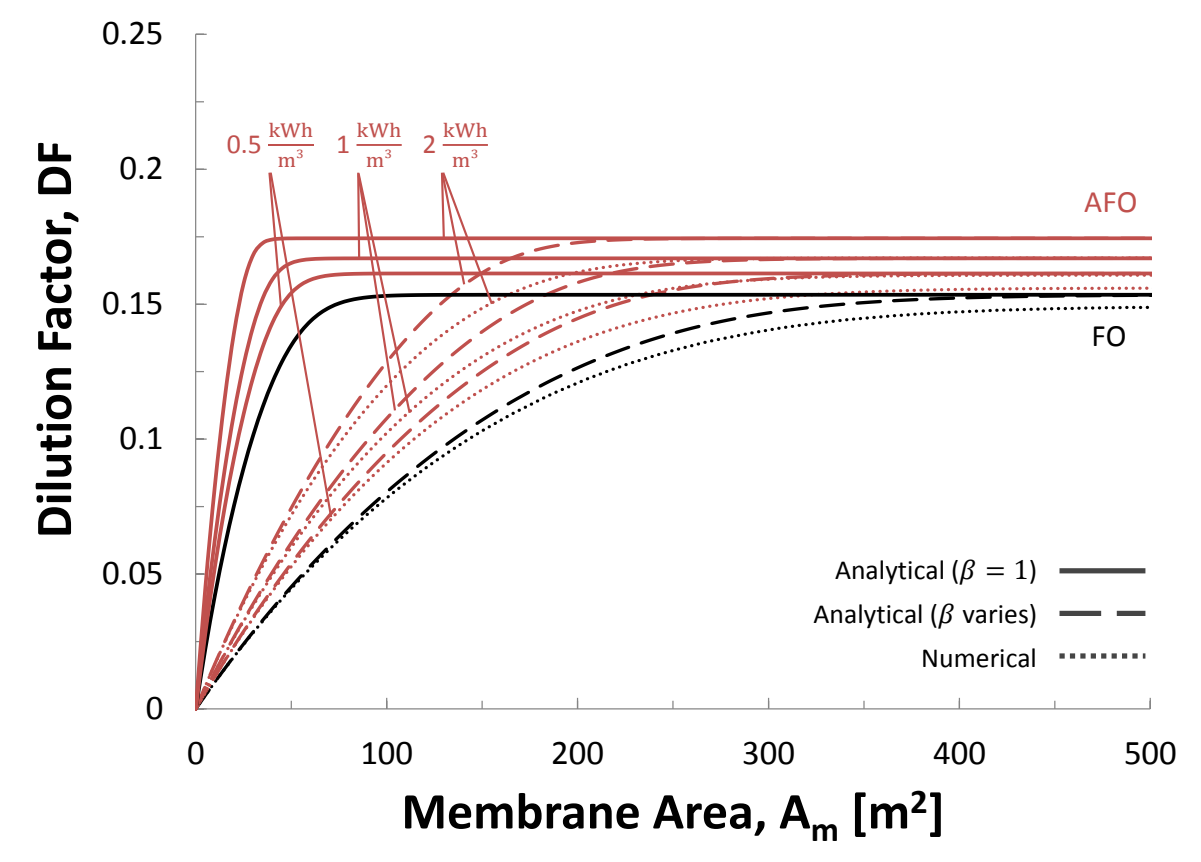

Figure 10: The membrane area requirement of forward osmosis (black line) and assisted forward osmosis systems (red lines) for a fertigation process with a seawater (35 ppt) feed, unity feed flow rate, and $\mathrm{MR}=4$. The analytical results with $\beta=1$ are presented with solid lines, analytical results with varying $\beta$ are presented with dashed lines, and numerical results are presented with dotted lines.

In both cases we observe large deviations between the analytical model where $\beta$ is unity and the numerical model. Errors in the analytical model are significantly reduced, however, by using a single value of $\beta$ as given for each case in Table 2. The percent error in the required membrane area for a given dilution using the analytical model for varying and 


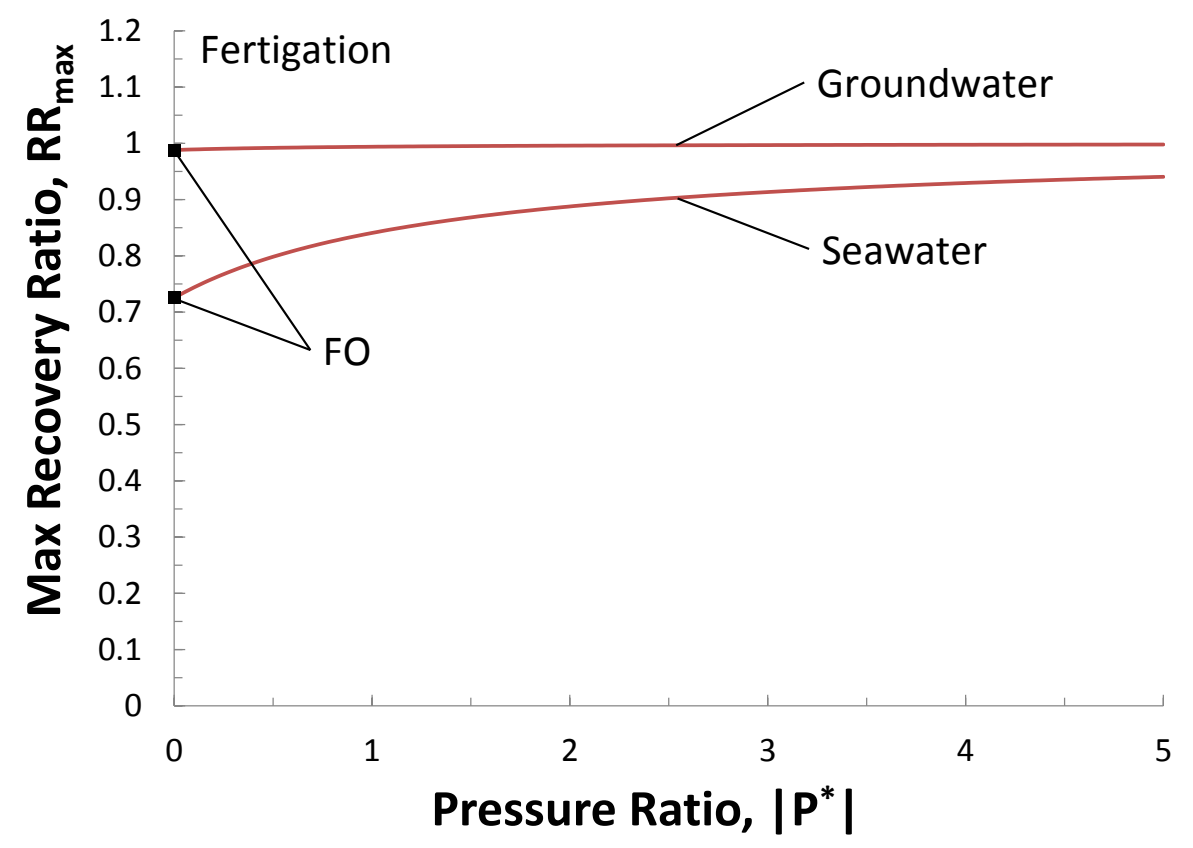

Figure 11: The maximum recovery ratio versus applied pressure ratio for groundwater and seawater feeds 


\begin{tabular}{lcccccc} 
Brackish feed errors & \multicolumn{2}{c}{$\beta$ varies } & \multicolumn{2}{c}{$\beta=1$} & \multicolumn{2}{c}{ Linear Est. } \\
Energy input $\left(\mathrm{kWh} / \mathrm{m}^{3}\right)$ & $\mathrm{DF}(\%)$ & $A_{m}(\%)$ & $\mathrm{DF}(\%)$ & $A_{m}(\%)$ & $\mathrm{DF}(\%)$ & $A_{m}(\%)$ \\
\hline 0.0 & 0.5 & 1.6 & 36.3 & 58.5 & 24.9 & 18.7 \\
0.5 & 0.6 & 2.1 & 31.7 & 59.5 & 21.9 & 18.5 \\
1.0 & 0.8 & 3.0 & 29.2 & 60.9 & 25.6 & 18.6 \\
2.0 & 0.9 & 4.0 & 25.7 & 64.2 & 20.8 & 18.4
\end{tabular}

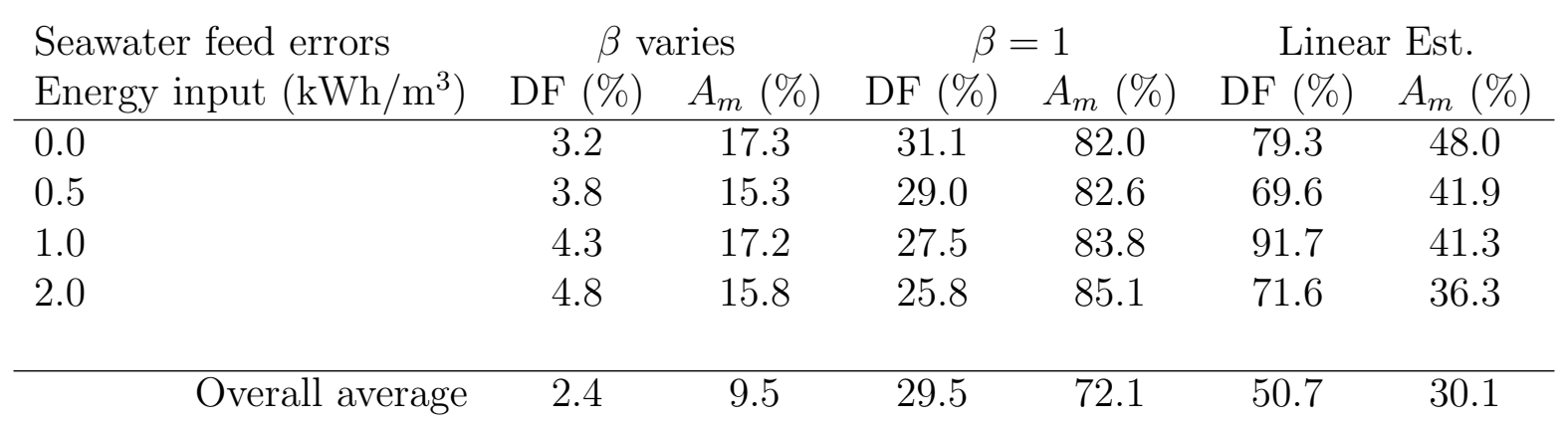

Table 3: Average error in dilution factor (DF) and membrane area $\left(A_{m}\right)$ for the FO and AFO analytical models using varying and unity values of $\beta$ in the fertigation case study. Errors incurred from linearly extrapolating Eq. 33 are also included. Overall average errors across cases and energy inputs are presented. Error calculations were terminated when the maximum recovery ratio was reached.

unity values of $\beta$ is plotted for the groundwater and seawater cases in Figs. 12 and 13. The average percentage errors in computing the dilution factor and required membrane area are presented in Table 3 for three scenarios: $\beta$ varies, $\beta=1$, and a linear extrapolation of Eq. 33 as is commonly done for size estimation. Table 3 shows that errors generally increase for increasing feed salinity and greater energy input to the AFO system. Although not displayed in the table, maximum errors were found to be high for $\beta=1$ and linear estimation models and low for the varying $\beta$ model.

In summary, use of our analytical model along with a $\beta$ value calculated by following Section 5 results in overall average errors of less than $10 \%$ against the numerical model.

\section{Conclusions}

A model that considers the change in osmotic driving force along the length of the membrane must be used to properly design a system scale FO or AFO exchanger. This work provides analytical expressions for counterflow and parallel-flow configurations which account for internal and external concentration polarization. These expressions allow designers to quickly estimate the required membrane area for a dilution or concentration process using $\mathrm{FO}$ or AFO with average errors of less than 10\% against a numerical model and less than $35 \%$ validated against data from literature. We show that diminishing returns in recovery ratio are attained for increasing membrane area and increasing mass flow rate ratios and that designers should design systems to operate at the 'knee' of these curves. We also find that 


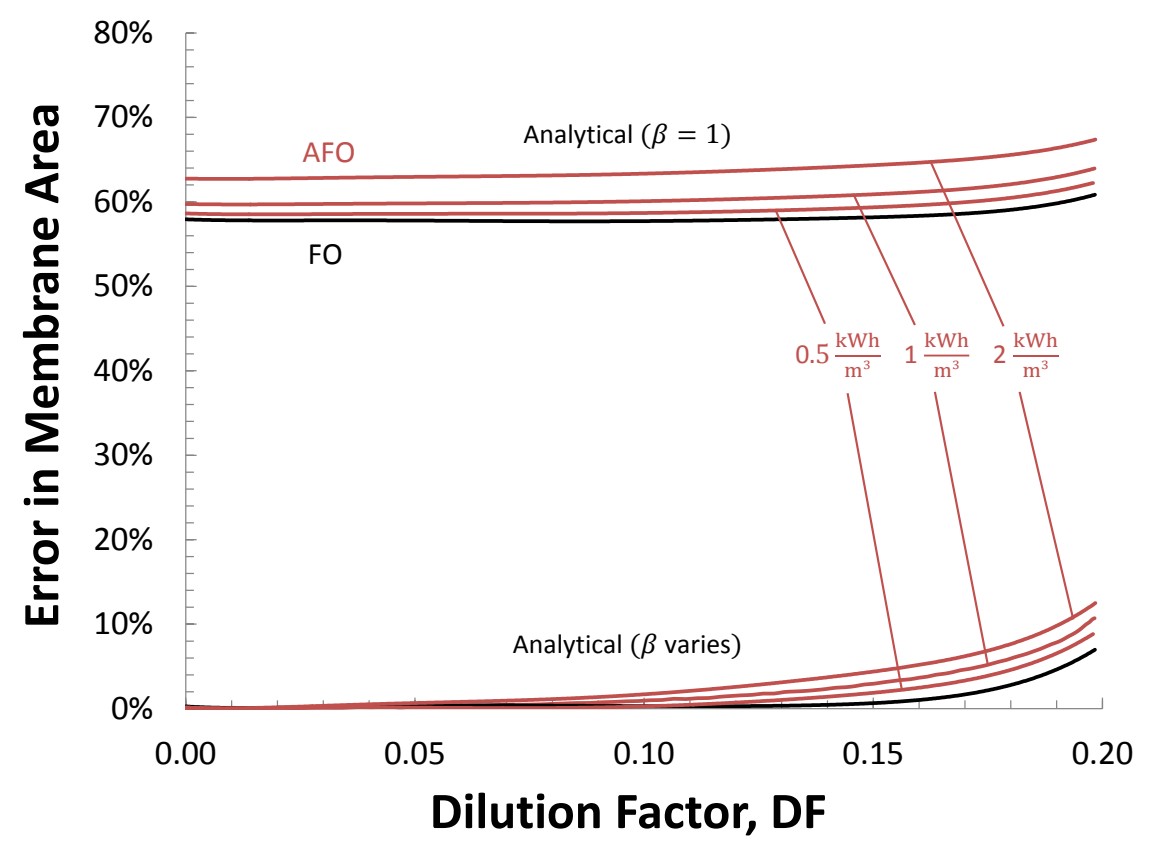

Figure 12: The error in membrane area between the analytical ( $\beta=1$ and $\beta$ varies) and numerical approaches for modeling fertigation with a groundwater (1.5 ppt) feed. 


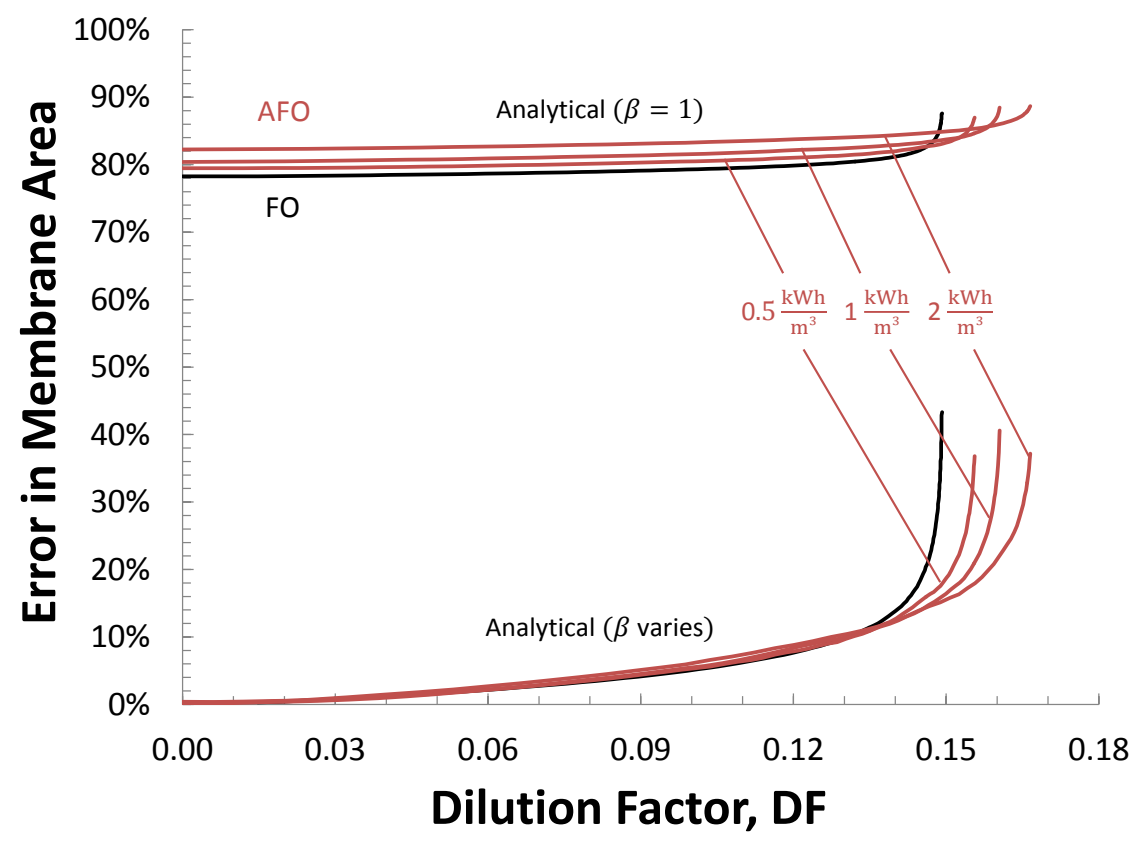

Figure 13: The error in membrane area between the analytical ( $\beta=1$ and $\beta$ varies) and numerical approach for modeling fertigation with a seawater $(35 \mathrm{ppt})$ feed. Error contours increase sharply after $\mathrm{DF}=0.14$ due to a difference in $\mathrm{DF}$ vs. $A_{m}$ asymptotic limits for numerical and analytical solutions. 
AFO exchangers yield a higher recovery relative to FO exchangers for a given energy input especially when the inlet draw-to-feed osmotic pressure ratio is low.

The analytical models are applied to a fertigation case study in which concentrated fertilizer (modeled as a $\mathrm{KCl}$ solution) is diluted with brackish groundwater or seawater for use in agriculture. A numerical model is used to determine the accuracy of the analytical models. The percentage decrease in the salinity of the entering fertilizer, or dilution factor, is calculated as a function of membrane area for a given inlet feed flow rate, mass flow rate ratio, feed concentration, and energy input to the AFO system. We find that the fertilizer salinity can be reduced by approximately $20 \%$ at most for a groundwater feed and by $15-18 \%$ for a seawater feed. To reach this dilution factor with a feed mass flow rate of $1 \mathrm{~kg} / \mathrm{s}$, an FO system will require $118 \mathrm{~m}^{2}$ of membrane area while an AFO system using $1 \mathrm{kWh} / \mathrm{m}^{3}$ will only require $84 \mathrm{~m}^{2}$; a $27 \%$ reduction in area. We also find the maximum recovery ratio for an AFO process increases more significantly for more concentrated feed streams with increasing feed hydraulic pressures.

\section{Acknowledgments}

The authors would like to thank Kuwait Foundation for the Advancement Sciences (KFAS) for their financial support through Project No. P31475EC01. LDB acknowledges that this material is based upon work supported by the National Science Foundation Graduate Research Fellowship Program under Grant No. 1122374. 


\section{References}

[1] IDA, Desalination Yearbook, Section 1. Market Profile. International Desalination Association, 2012 - 2013.

[2] T. Cath, A. Childress, and M. Elimelech, "Forward osmosis: Principles, applications, and recent developments," Journal of Membrane Science, vol. 287, pp. 70-87, 2006.

[3] C. Klaysom, T. Y. Cath, T. Depudt, and I. F. Vankelecom, "Forward and pressure retarded osmosis: potential solutions for global challenges in energy and water supply," Chemical Society Reviews, vol. 42, pp. 6959-6989, 2013.

[4] N. T. Hancock, M. S. Nowosielski-Slepowron, and L. S. Marchewka, "Application of forward osmosis based membrane brine concentrators for produced waters," in The International Desalination Association World Congress on Desalination and Water Reuse, Tianjin, China, 2013.

[5] R. K. McGovern and J.H. Lienhard V, "On the potential of forward osmosis to energetically outperform reverse osmosis desalination," Journal of Membrane Science, vol. 469, pp. $245-250,2014$.

[6] B. D. Coday, P. Xu, E. G. Beaudry, J. Herron, K. Lampi, N. T. Hancock, and T. Y. Cath, "The sweet spot of forward osmosis: Treatment of produced water, drilling wastewater, and other complex and difficult liquid streams," Desalination, vol. 333, pp. 23 - 35, 2014.

[7] D. L. Shaffer, L. H. Arias Chavez, M. Ben-Sasson, S. Romero-Vargas Castrilln, N. Y. Yip, and M. Elimelech, "Desalination and reuse of high-salinity shale gas produced water: Drivers, technologies, and future directions," Environmental Science $\&$ Technology, vol. 47, pp. 9569-9583, 2013.

[8] G. P. Thiel, E. W. Tow, L. D. Banchik, H. W. Chung, and J. H. Lienhard, "Energy consumption in desalinating produced water from shale oil and gas extraction," Desalination, vol. 366, pp. 94-112, 2015.

[9] E. W. Tow, R. K. McGovern, and J.H. Lienhard V, "Raising forward osmosis brine concentration efficiency through flow rate optimization," Desalination, vol. 366, pp. 71$79,2015$.

[10] K. Lee, R. Baker, and H. Lonsdale, "Membranes for power generation by pressureretarded osmosis," Journal of Membrane Science, vol. 8, pp. 141-171, 1981.

[11] T. Yun, Y. Kim, S. Lee, S. Hong, and G. Kim, "Flux behavior and membrane fouling in pressure assisted forward osmosis," Desalination and Water Treatment, vol. 52, pp. 564$569,2013$.

[12] J. Duan, E. Litwiller, and I. Pinnau, "Solution-diffusion with defects model for pressureassisted forward osmosis," Journal of Membrane Science, vol. 470, pp. 323 - 333, 2014. 
[13] K. Lutchmiah, D. J. Harmsen, B. A. Wols, L. C. Rietveld, J. Qin, and E. R. Cornelissen, "Continuous and discontinuous pressure assisted osmosis (PAO)," Journal of Membrane Science, vol. 476, pp. 182 - 193, 2015.

[14] G. Blandin, A. R. Verliefde, C. Y. Tang, A. E. Childress, and P. Le-Clech, "Validation of assisted forward osmosis (AFO) process: Impact of hydraulic pressure," Journal of Membrane Science, vol. 447, pp. 1-11, 2013.

[15] Y. Oh, S. Lee, M. Elimelech, S. Lee, and S. Hong, "Effect of hydraulic pressure and membrane orientation on water flux and reverse solute flux in pressure assisted osmosis," Journal of Membrane Science, vol. 465, pp. 159 - 166, 2014.

[16] B. D. Coday, D. M. Heil, P. Xu, and T. Y. Cath, "Effects of transmembrane hydraulic pressure on performance of forward osmosis membranes," Environmental Science 83 Technology, vol. 47, pp. 2386-2393, 2013.

[17] S. Phuntsho, H. K. Shon, S. Hong, S. Lee, and S. Vigneswaran, "A novel low energy fertilizer driven forward osmosis desalination for direct fertigation: Evaluating the performance of fertilizer draw solutions," Journal of Membrane Science, vol. 375, pp. 172 $-181,2011$.

[18] Y.-J. Choi, J.-S. Choi, H.-J. Oh, S. Lee, D. R. Yang, and J. H. Kim, "Toward a combined system of forward osmosis and reverse osmosis for seawater desalination," Desalination, vol. 247, pp. 239 - 246, 2009.

[19] A. Sagiv and R. Semiat, "Finite element analysis of forward osmosis process using $\mathrm{NaCl}$ solutions," Journal of Membrane Science, vol. 379, pp. 86-96, 2011.

[20] D. Xiao, W. Li, S. Chou, R. Wang, and C. Y. Tang, "A modeling investigation on optimizing the design of forward osmosis hollow fiber modules," Journal of Membrane Science, vol. 392-393, pp. 76 - 87, 2012.

[21] R. W. Holloway, A. E. Childress, K. E. Dennett, and T. Y. Cath, "Forward osmosis for concentration of anaerobic digester centrate," Water Research, vol. 41, no. 17, pp. 4005 - 4014, 2007. Membranes.

[22] S. Phuntsho, S. Hong, M. Elimelech, and H. K. Shon, "Osmotic equilibrium in the forward osmosis process: Modelling, experiments and implications for process performance," Journal of Membrane Science, vol. 453, pp. 240 - 252, 2014.

[23] A. Deshmukh, N. Yip, S. Lin, and M. Elimelech, "Desalination by forward osmosis: Indentifying performance limiting parameters through module-scale modeling," Journal of Membrane Science, vol. 491, pp. 159-167, 2015.

[24] W. Kays and A. London, Compact Heat Exchangers 3rd ed. McGraw-Hill, 1984.

[25] M. H. Sharqawy, L. D. Banchik, and J. H. Lienhard V, "Effectiveness-mass transfer units ( $\epsilon$-MTU) model of an ideal pressure retarded osmosis membrane mass exchanger," Journal of Membrane Science, vol. 445, pp. 211-219, 2013. 
[26] L. D. Banchik, M. H. Sharqawy, and J. H. Lienhard V, "Effectiveness-mass transfer units ( $\epsilon$-MTU) model of a reverse osmosis membrane mass exchanger," Journal of Membrane Science, vol. 458, pp. 189-198, 2014.

[27] L. D. Banchik, M. H. Sharqawy, and J. H. Lienhard V, "Limits of power production due to finite membrane area in pressure retarded osmosis," Journal of Membrane Science, vol. 468 , pp. $81-89,2014$.

[28] J. McCutcheon and M. Elimelech, "Modeling water flux in forward osmosis: implications for improved membrane design," American Institute of Chemical Engineers Journal, vol. 53, pp. 1736-1744, 2007.

[29] R. K. McGovern, J. Mizerak, S. M. Zubair, and J.H. Lienhard V, "Three dimensionless parameters influencing the optimal membrane orientation for forward osmosis," Journal of Membrane Science, vol. 458, pp. 104-110, 2014.

[30] K. Pitzer, Thermodynamics 3rd ed. McGraw-Hill, 1995.

[31] S. Klein, "Engineering equation solver v8.881-3d." F-Chart Software, February 2011.

[32] Y. Xu, X. Peng, C. Tang, Q. Fu, and S. Nie, "Effect of draw solution concentration and operating conditions on forward osmosis and pressure retarded osmosis performance in a spiral wound module," Journal of Membrane Science, vol. 348, pp. 298-309, 2010.

[33] C. Tan and H. Ng, "Revised external and internal concentration polarization models to improve flux prediction in forward osmosis process," Desalination, vol. 309, pp. 125-140, 2013. 


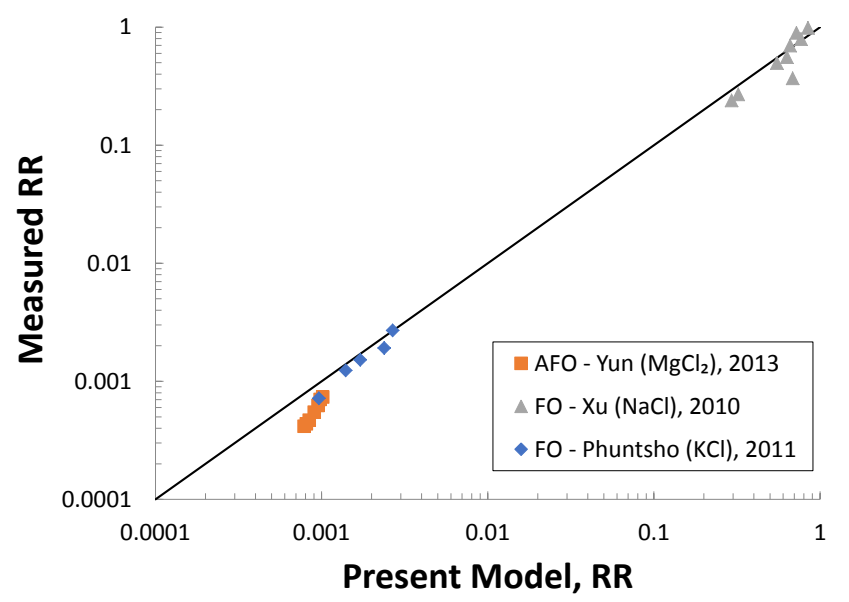

Figure 14: Log-log plot of measured recovery ratio vs. recovery ratio calculated by the present analytical model. Sources: [11], [17], and [32]. Error bars have not been included because uncertainty analysis for the experimental data was not performed in the literature sources.

\section{A Validating model with literature data}

The analytical counterflow FO and AFO models were validated using literature data from [11], [17], and [32]. The literature data span a range of draw stream chemical composition $\left(\mathrm{KCl}, \mathrm{MgCl}_{2}\right.$, and $\mathrm{NaCl}$ ) and operating conditions. $\mathrm{Xu}$ et al. [32] use a spiral wound $\mathrm{FO}$ module with spacers and Yun et al. [11] use assisted forward osmosis.

To validate the models, $\beta$ was calculated using the methodology outlined in Section 5 for the FO mode orientation (membrane active layer facing feed solution) which was used in each source. The resulting $\beta$ values were used along with the relevant dimensionless parameters to predict the recovery ratio. Where necessary, the diffusion coefficient, density, and dynamic viscosity were calculated from correlations compiled by Tan et al. [33]. Figure 14 shows empirical recovery ratios from literature compared to recovery ratios calculated by the present analytical model.

The range of independent variables spanned by the validation is: $7.87 \times 10^{-4}<\mathrm{RR}<0.85$; $0.54<\mathrm{MR}<1.25 ; 7.94 \times 10^{-4}<\mathrm{MTU}_{\pi}<1.20 ; 0.16<\beta<0.81 ; 432.60<\Delta \pi_{\max }[\mathrm{kPa}]<$ $1.39 \times 10^{4} ;-0.23<P^{*}<0 ; 4.20 \times 10^{-6}<k_{f}[\mathrm{~m} / \mathrm{s}]<2.18 \times 10^{-5} ;$ and $1.92 \times 10^{5}<K[\mathrm{~s} / \mathrm{m}]<$ $3.82 \times 10^{5}$. Because de-ionized water was used as the feed in all literature data, $\theta_{f}=0$ and $\theta_{d}=1$. The average error for FO and AFO data was $19.97 \%$ and $64.79 \%$, respectively. The mean error across all data is $34.91 \%$.

\section{B One-dimensional parallel-flow models}

The utility of parallel-flow exchangers is severely limited in that they yield significantly lower recovery ratios for the same membrane area. Nevertheless, for completeness, we include the analytical models for assisted forward osmosis and forward osmosis exchangers operated in 
parallel-flow. To develop these expressions, we invoke the same assumptions used in the development of the counterflow exchanger models. Although it is outside the scope of this work, Section 5 can also be used to determine $\beta$ values to reduce errors for the parallel-flow analytical AFO and FO models.

\section{B.1 Assisted forward osmosis}

For the AFO parallel-flow configuration, we rewrite the draw salinity as a function of axial position for the counterflow case Eq. (6), to start from the feed inlet side:

$$
w_{d}(x)=\frac{\dot{m}_{d, i} \times w_{d, i}}{\dot{m}_{d, i}+\dot{m}_{p}(x)}
$$

Substituting Eqs. (5) and (B.1) into Eq. (2) yields

$$
d \dot{m}_{p}=A\left[f_{\mathrm{os}}\left(\frac{\dot{m}_{d, i} \times w_{d, i}}{\dot{m}_{d, i}+\dot{m}_{p}}-\frac{\dot{m}_{f, i} \times w_{f, i}}{\dot{m}_{f, i}-\dot{m}_{p}}\right)-\Delta P\right] \beta d A_{m}
$$

With some algebra and substitution of the dimensionless parameters described in Sec. 3.1:

$$
d \mathrm{RR}=\left(\frac{\mathrm{MR} \times \theta_{d}}{\mathrm{MR}+\mathrm{RR}}-\frac{\theta_{f}}{1-\mathrm{RR}}-P^{*}\right) d \mathrm{MTU}_{\pi}
$$

Equation (B.3) can be integrated and simplified:

$$
\int_{0}^{\mathrm{RR}} \frac{(\mathrm{MR}+\mathrm{RR})(1-\mathrm{RR})}{P^{*}\left(\mathrm{RR}-\kappa^{\prime}\right)\left(\mathrm{RR}-\lambda^{\prime}\right)} d \mathrm{RR}=\mathrm{MTU}_{\pi}
$$

where

$$
\begin{aligned}
\kappa^{\prime}= & \frac{1}{2 P^{*}}\left(P^{*}+\operatorname{MR}\left(\theta_{d}-P^{*}\right)+\theta_{f}\right) \\
& -\frac{1}{2 P^{*}} \sqrt{\left(P^{*}+\operatorname{MR}\left(\theta_{d}-P^{*}\right)+\theta_{f}\right)^{2}-4 \operatorname{MR} P^{*}\left(\theta_{d}-\theta_{f}-P^{*}\right)} \\
\lambda^{\prime}= & \frac{1}{2 P^{*}}\left(P^{*}+\operatorname{MR}\left(\theta_{d}-P^{*}\right)+\theta_{f}\right) \\
& +\frac{1}{2 P^{*}} \sqrt{\left(P^{*}+\operatorname{MR}\left(\theta_{d}-P^{*}\right)+\theta_{f}\right)^{2}-4 \operatorname{MR} P^{*}\left(\theta_{d}-\theta_{f}-P^{*}\right)}
\end{aligned}
$$

Therefore the integration of Eq. (B.4) will be

$$
\begin{aligned}
\mathrm{MTU}_{\pi} \times P^{*}= & \frac{\left(\lambda^{\prime}-1\right)\left(\mathrm{MR}+\lambda^{\prime}\right)}{\left(\kappa^{\prime}-\lambda^{\prime}\right)} \ln \left(\frac{\lambda^{\prime}-\mathrm{RR}}{\lambda^{\prime}}\right) \\
& -\frac{\left(\kappa^{\prime}-1\right)\left(\mathrm{MR}+\kappa^{\prime}\right)}{\left(\kappa^{\prime}-\lambda^{\prime}\right)} \ln \left(\frac{\kappa^{\prime}-\mathrm{RR}}{\kappa^{\prime}}\right)-\mathrm{RR}
\end{aligned}
$$

Figure 15 shows the recovery ratio attainable as a function of $\mathrm{MTU}_{\pi}$ for contours of $\mathrm{MR}$, $\theta_{d}=2$ and $\theta_{f}=1$, and a pressure difference of feed to draw equal to the maximum osmotic 


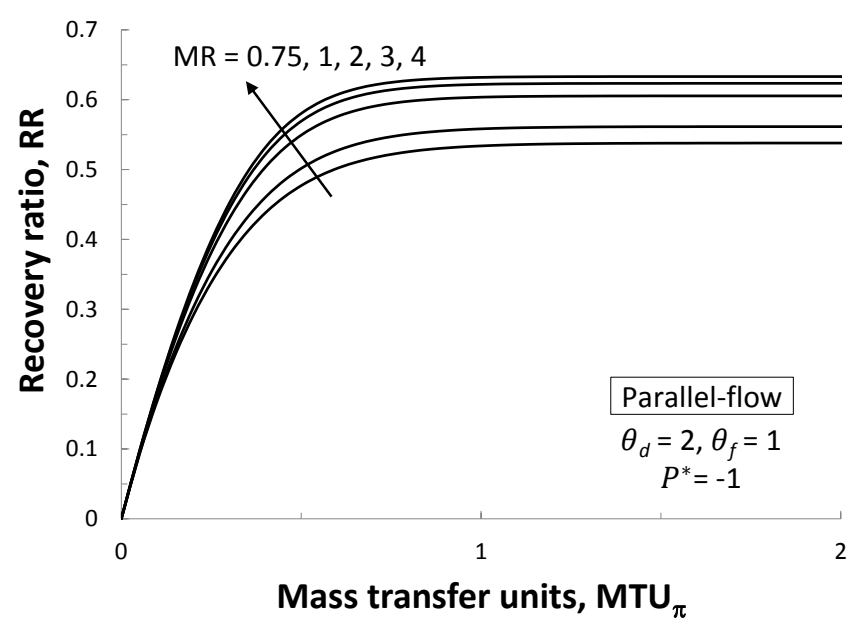

Figure 15: Recovery ratio vs. mass transfer units with contours of mass flow rate ratio for a parallel-flow AFO exchanger where $-\Delta P=\Delta \pi_{\max }$, i.e. $P^{*}=-1$.

pressure difference $P^{*}=-1$. The choice of parameters represents a case where the draw osmotic pressure is two times greater than the feed, such as for a seawater feed stream and brine from a seawater desalination system with $50 \%$ recovery.

To find the maximum recovery ratio of the parallel-flow case, we equate the net driving potential to zero at the outlet of the exchanger:

$$
\Delta \pi_{o}=\pi_{d, o}-\pi_{f, o}=f_{\mathrm{os}}\left(w_{d, o}-w_{f, o}\right)=\Delta P
$$

Substituting conservation of solution and solutes for the draw and feed streams to express the outlet salinities in terms of the inlet salinities and other dimensionless variables, and dividing by $\Delta \pi_{\max }$, yields the following expression:

$$
\frac{\theta_{d} \mathrm{MR}}{\mathrm{MR}+\mathrm{RR}_{\max }}-\frac{\theta_{f}}{1-\mathrm{RR}_{\max }}=P^{*}
$$

Solving for $\mathrm{RR}_{\max }$ yields two roots, $\kappa^{\prime}$ and $\lambda^{\prime}$, as defined in Eqs. B.5 and B.6. Taking the maximum recovery ratio which is less than unity, we find the maximum recovery ratio:

$$
\mathrm{RR}_{\max }=\kappa^{\prime}
$$

The effectiveness is defined by Eq. (23) and is plotted versus $\mathrm{MTU}_{\pi}$ for the parallel-flow configuration with MR contours in Fig. 16.

\section{B.2 Forward osmosis}

For the FO parallel-flow configuration, we substitute Eq. (B.1) into Eq. (18), then use the dimensionless groups given in Sec. 3.1 which yields:

$$
d \mathrm{RR}=\left(\frac{\mathrm{MR} \times \theta_{d}}{\mathrm{MR}+\mathrm{RR}}-\frac{\theta_{f}}{1-\mathrm{RR}}\right) d \mathrm{MTU}_{\pi}
$$




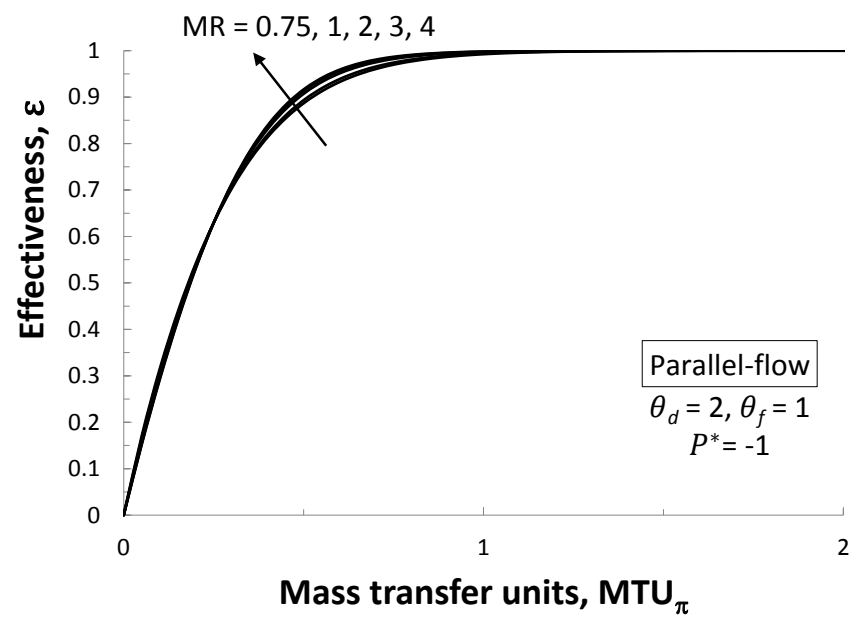

Figure 16: Effectiveness vs. mass transfer units with contours of mass flow rate ratio for a parallel-flow AFO exchanger where $-\Delta P=\Delta \pi_{\max }$, i.e. $P^{*}=-1$.

Equation (B.11) can be integrated as follows:

$$
\int_{0}^{\mathrm{RR}} \frac{(\mathrm{MR}+\mathrm{RR})(1-\mathrm{RR})}{\mathrm{MR} \theta_{d}(1-\mathrm{RR})-\theta_{f}(\mathrm{MR}+\mathrm{RR})} d \mathrm{RR}=\mathrm{MTU}_{\pi}
$$

Evaluation of the integral in Eq. (B.12) yields,

$$
\begin{aligned}
\mathrm{MTU}_{\pi}= & \frac{\mathrm{MR}}{f^{\prime}} \ln \left|\frac{g^{\prime}}{e^{\prime}}\right|+(1-\mathrm{MR})\left(\frac{\mathrm{RR}}{f^{\prime}}+\frac{e^{\prime}}{f^{\prime 2}} \ln \left|\frac{e^{\prime}}{g^{\prime}}\right|\right) \\
& +\frac{1}{f^{\prime 3}}\left[e^{\prime 2}\left(\ln \left|\frac{e^{\prime}}{g^{\prime}}\right|-\frac{3}{2}\right)+2 e^{\prime} g^{\prime}-\frac{g^{\prime 2}}{2}\right]
\end{aligned}
$$

where

$$
\begin{aligned}
& e^{\prime}=\operatorname{MR}\left(\theta_{d}-\theta_{f}\right) \\
& f^{\prime}=-\left(\operatorname{MR} \theta_{d}+\theta_{f}\right) \\
& g^{\prime}=e^{\prime}+f^{\prime} \times \operatorname{RR}
\end{aligned}
$$

Figure 17 shows the recovery ratio $\mathrm{RR}$ increase with the number of mass transfer units $\mathrm{MTU}_{\pi}$ for contours of $\mathrm{MR}$ in the parallel-flow configuration. The choice of parameters represents a case where the draw osmotic pressure is two times greater than the feed, such as for a seawater feed stream and brine from a seawater desalination system with $50 \%$ recovery.

To find the maximum recovery ratio of the parallel-flow case, we equate the osmotic driving potential to zero at the outlet of the exchanger:

$$
\Delta \pi_{o}=\pi_{d, o}-\pi_{f, o}=f_{\text {os }}\left(w_{d, o}-w_{f, o}\right)=0
$$




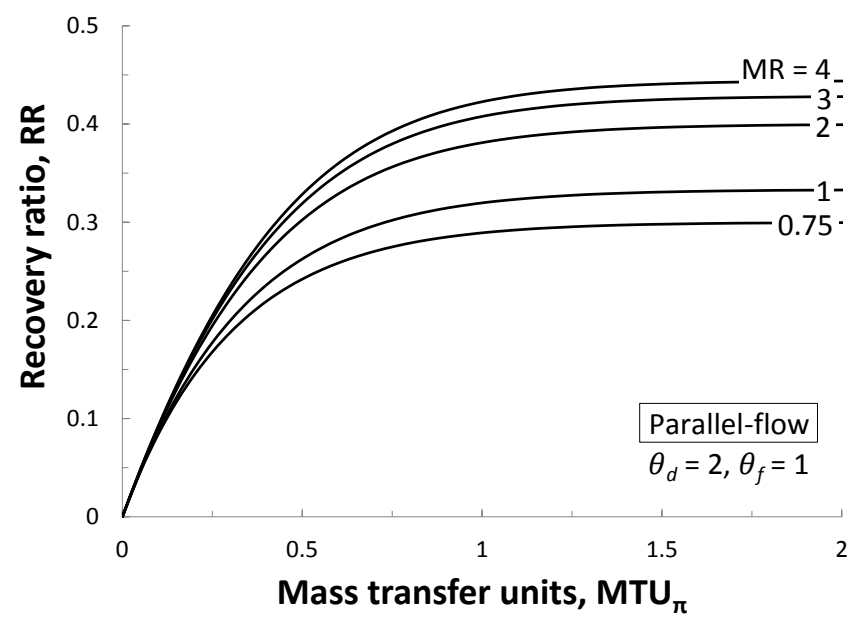

Figure 17: Recovery ratio vs. mass transfer units with contours of mass flow rate ratio for a parallel-flow FO exchanger.

Substituting conservation of solution and solutes for the draw and feed streams to express the outlet salinities in terms of the inlet salinities and other dimensionless variables, and dividing by $\Delta \pi_{\max }$, yields the following expression:

$$
\frac{\theta_{d} \mathrm{MR}}{\mathrm{MR}+\mathrm{RR}_{\max }}-\frac{\theta_{f}}{1-\mathrm{RR}_{\max }}=0
$$

Solving for $\mathrm{RR}_{\max }$ yields:

$$
\mathrm{RR}_{\max }=\frac{\mathrm{MR}}{\theta_{d} \mathrm{MR}+\theta_{f}}
$$

The effectiveness is defined by Eq. (23) and is plotted versus $\mathrm{MTU}_{\pi}$ for the parallel-flow configuration with MR contours in Fig. 18. 


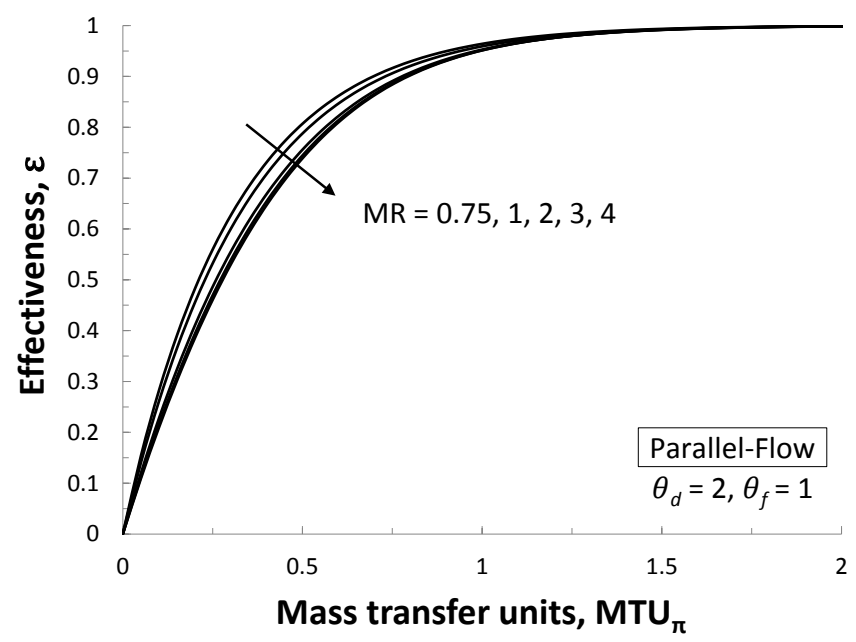

Figure 18: Effectiveness vs. mass transfer units with contours of mass flow rate ratio for a parallel-flow configuration in FO operation. 